\title{
Ultradian feeding in mice not only affects the peripheral clock in the liver, but also the master clock in the brain
}

\author{
Satish Sen ${ }^{\mathrm{a}, \mathrm{b}, \mathrm{c}}$, Hélène Raingard ${ }^{\mathrm{a}}$, Stéphanie Dumont ${ }^{\mathrm{a}}$, Andries Kalsbeek ${ }^{\mathrm{b}, c, \mathrm{~d}}$, Patrick Vuillez ${ }^{\mathrm{a}, \mathrm{c}}$, and \\ Etienne Challet ${ }^{\mathrm{a}, \mathrm{d}}$
}

aRegulation of Circadian Clocks team, Institute of Cellular and Integrative Neurosciences, UPR3212, Centre National de la Recherche Scientifique (CNRS), University of Strasbourg, France; ${ }^{b}$ Hypothalamic Integration Mechanisms, Netherlands Institute for Neuroscience (NIN), Amsterdam, The Netherlands; International Associated Laboratory LIA1061 Understanding the Neural Basis of Diurnality, CNRS, France and The Netherlands; ${ }^{d}$ Department of Endocrinology and Metabolism, Academic Medical Center (AMC), University of Amsterdam, The Netherlands.

\section{ABSTRACT}

Restricted feeding during the resting period causes pronounced shifts in a number of peripheral clocks, but not the central clock in the suprachiasmatic nucleus (SCN). By contrast, daily caloric restriction impacts also the light-entrained SCN clock, as indicated by shifted oscillations of clock (PER1) and clock-controlled (vasopressin) proteins. To determine if these SCN changes are due to the metabolic or timing cues of the restricted feeding, mice were periodicity of feeding. Mice fed with ultradian feeding that lost $<10 \%$ body mass (i.e. isocaloric) displayed 1.5-h phase-advance of body temperature rhythm, but remained mostly nocturnal, together with up-regulated vasopressin and down-regulated PER1 and PER2 levels in the SCN. Hepatic expression of clock genes (Per2, Rev-erba, and Clock) and Fgf 21 was,
respectively, phase-advanced and up-regulated by ultradian feeding. Mice fed with ultradian feeding that lost $>10 \%$ body mass (i.e. hypocaloric) became more diurnal, hypothermic in late night, and displayed larger ( $3.5 \mathrm{~h})$ advance of body temperature rhythm, more reduced PER1 expression in the SCN, and further modified gene expression in the liver (e.g. larger phase-advance of Per2 and up-regulated levels of Pgc-1a). While glucose rhythmicity was lost under ultradian feeding, the phase of daily rhythms in liver glycogen and plasma corticosterone (albeit increased in amplitude) remained unchanged. In conclusion, the additional impact of hypocaloric conditions on the SCN are mainly due to the metabolic and not the timing effects of restricted daytime feeding.

\section{KEYWORDS}

circadian rhythm; feeding; 6-meal schedule; clock gene; suprachiasmatic nucleus

\section{Introduction}

Biological rhythms are under the control of circadian oscillators, including a master circadian clock located in the suprachiasmatic nucleus (SCN) of the anterior hypothalamus and peripheral oscillators present in almost every cell of the body (Bray \& Young, 2009). The underlying molecular mechanism of the clock is based on transcriptional and translational feedback loops consisting of positive and negative elements (Reppert \& Weaver, 2001). When heterodimerized, the positive limb elements BMAL1 and CLOCK activate transcription of the negative elements (Period (Per)1, 2, 3 and Cryptochrome (Cry)1, 2) that in turn inhibit BMAL1/CLOCK transactivation. In parallel, other clock genes such as Rev-erb $\alpha, \beta$ and Ror $\alpha, \beta$, whose transcription is also activated by BMAL1/CLOCK, modulate Bmall and Clock transcription (Cho et al., 2012; Crumbley \& Burris, 2011; Preitner et al., 2002). Light perceived by the retina is the most potent synchronizer of the circadian rhythm produced by the molecular clock mechanism within the SCN. The molecular clockwork regulates the rhythmic transcription of clock-controlled genes, such as the gene coding for neuropeptide Arginine Vasopressin $(A v p)$ (Jin et al., 1999). The output of the SCN controls the timing of peripheral clocks via nervous, hormonal and behavioral cues (Froy, 2011). Food access restricted to the usual resting period can phase-shift circadian oscillations in a number of peripheral organs and brain regions outside the SCN, while the SCN master clock remains 
synchronized to the light-dark cycle (Damiola et al., 2000; Feillet et al., 2008; Stokkan et al., 2001).

However, when daytime restricted feeding is combined with caloric restriction, the master clock is affected, as assessed by phase-advances in daily rhythms of body temperature, activity rhythm, and pineal melatonin, as well as by altered photic resetting (Challet, 2010). Moreover, daily caloric restriction leads to phase-shifts in daily oscillations of clock (PER1) and clock-controlled (AVP) proteins in the SCN (Mendoza et al., 2007). To avoid the synchronizing effects of daily restricted feeding, a protocol has been developed using a feeding regimen of six 10 -min food accesses equally distributed over $24 \mathrm{~h}$ (i.e. one 10-min meal every $4 \mathrm{~h}$ ) (Kalsbeek \& Strubbe, 1998). In nocturnal rats under light-dark conditions, this ultradian 6-meals-a-day feeding schedule does not modify the phase of locomotor activity rhythm, but if food access to the 6-meals is shortened to cause body mass loss, rats become partially active during daytime due to a phaseadvance of the rest/activity rhythm (Mendoza et al., 2008).

One recent rat study showed that peripheral clock gene rhythms are still present during ultradian 6-meals-a-day feeding, despite changes in amplitude and phase ( $\mathrm{Su}$ et al., 2016b). Another study suggested that in mice, the peripheral clocks remain unaffected by meal timing when each meal is given equally spaced either 2, 3, 4 or 6 times per day. However, if meal frequency is unevenly distributed, i.e. with unequal intervals between the meals, then the phase of peripheral clock genes changes, especially in the kidney. Moreover, that study also showed that ultradian 6-meal feeding coupled to caloric restriction was able to produce phase-advances of peripheral clocks inversely proportional to the degree of energy intake (Kuroda et al., 2012).

In the present study, we aimed at investigating further whether it is the daily timing of feeding and fasting or metabolic cues associated with calo-

105 ric restriction that affects the central and peripheral clocks. For that purpose, we challenged mice with a 6-meals-a-day feeding schedule (combined with isocaloric or hypocaloric conditions) and studied their behavioural and physiological changes,

110 as well as expression of clock and clock-controlled genes in the master clock and liver.

\section{Materials and methods}

\section{Animals and housing}

Seventy-six 5-week old male C57BL/6J mice (Janvier labs, Le Genest-Saint-Isle, France) were used for this study. The animals were housed in individual cages equipped with a wheel, at an ambient temperature of $23 \pm 2^{\circ} \mathrm{C}$ under $12: 12 \mathrm{~h}$ light-dark conditions (lights on at 7:00 AM (defining Zeitgeber Time (ZT) 0) and off at 19:00 PM (=ZT12)). In a group of 46 animals, access to food was automatically controlled by electronic timers for six cages at a time. Thirty animals served as controls and had ad libitum access to food.

All experiments were performed in accordance with the U.S. National Institutes of Health Guide for the Care and Use of Laboratory Animals (1996), the French National Law (implementing the European Communities Council Directive 86/ $609 / \mathrm{EEC}$ ) and approved in advance by the Regional Ethical Committee of Strasbourg for Animal Experimentation (AL/50/57/02/13) and in compliance with the ethical standards of the journal (Portaluppi et al., 2010).

\section{Surgery}

Mice were anesthetized with isoflurane (Vetflurane, Virbac $3 \%$ powered by $0.2 \mathrm{l} / \mathrm{min} \mathrm{O} 2$ ) to implant a transponder (Minimitter, Vitalview, Sunriver, OR, USA) in the abdominal cavity to record body temperature and general cage activity. The abdomen was shaved and sprayed with antiseptic (DermaSpray, Bayer) before an incision in the skin and muscle $(8-10 \mathrm{~mm})$ was made. Once the transponder was inserted into the abdominal cavity, the muscle layer was stitched with surgical sutures (Filapeau, 3.0) and anti-inflammatory medication was provided in drinking water (Metacam, 0.2 $\mathrm{mg} / \mathrm{ml}, 0.1 \mathrm{ml}$ ) for 2 days.

\section{Experimental procedure}

After surgery, the animals were placed in experimental cages for 2 weeks with drinking water and food ad libitum. After this, mice were habituated to an ultradian schedule of six meals each day with one food access every 4 h (ZT2, ZT6, ZT10, ZT14, ZT18 and 
ZT22). Access to food during restricted feeding was set automatically by the Food Planning system based on a food basket allowing and preventing food access in the low and upper position, respectively 160 (Intellibio, Seichamps, France). Lifting and fall of the food basket being associated with a brief motor noise, these auditory cues may have signaled food availability to the mice. The smaller mesh size of the trough compared to the size of the food pellets prevented any food hoarding in the cage. The duration of food access was reduced every 4 days gradually from $6 \times 1 \mathrm{~h}$, via $6 \times 30 \mathrm{~min}, 6 \times 20 \mathrm{~min}$ to $6 \times 15$ min. This protocol was based on previous studies in rats (Kalsbeek \& Strubbe, 1998; Mendoza et al.,

170 2008). The fact that mice were fed every day at the same times has probably improved their ability to adjust to ultradian feeding, as opposed to irregular meal times (Valle, 1981). Food intake during daytime and nighttime was measured twice (at the steps 175 of $6 \times 1 \mathrm{~h}$ and $6 \times 15 \mathrm{~min}$ ) to evaluate the day-night pattern of food intake. The body mass was measured weekly. At the end of two weeks of feeding according to the $6 \times 15 \mathrm{~min}$ protocol, two groups were categorized according to individual adaptation to 180 the paradigm, eventually leading to body mass loss. A cut-off at $10 \%$ body mass loss allowed to distinguish an isocaloric group including animals with less than $10 \%$ of body mass loss (mean: $5.4 \pm 0.5 \%$; $n$ total $=24 ; n=4$ per ZT) and a hypocaloric group in which

185 animals lost $10 \%$ or more (up to $25 \%$ ) body mass (mean: $15.5 \pm 1.1 \%$; $n$ total $=22 ; n=3-4$ per ZT). Animals of the control group were kept with food and water ad libitum ( $n=5$ per ZT).

\section{Immunohistochemistry}

190 At the end of the experiment, animals were sacrificed with an overdose of pentobarbital. Mice fed with ultradian 6-meals schedule were sampled every $4 \mathrm{~h}$ between food accesses (i.e. ZT0, ZT4, ZT8, ZT12, ZT16 and ZT20) to limit direct effects of feeding 195 while avoiding prolonged fasting. Control mice fed ad libitum were sacrificed at the same times. Blood was sampled by intracardiac puncture, liver was sampled in the right lobe, and the heart was perfused with $50 \mathrm{~mL}$ of $0.9 \%$ saline followed by $50 \mathrm{~mL}$ of $4 \%$ 200 paraformaldehyde in phosphate buffer $(0.1 \mathrm{M}, \mathrm{pH}$ 7.4). Brains were removed, postfixed overnight in $4 \%$ paraformaldehyde $\left(4^{\circ} \mathrm{C}\right)$ and transferred to a cryoprotectant buffered sucrose solution $\left(30 \%\right.$ at $4^{\circ}$ C) for at least $24 \mathrm{~h}$ till brains sank to the bottom due to the sucrose density gradient. Brains were then frozen in isopentane around $-50^{\circ} \mathrm{C}$ and stored at $-80^{\circ} \mathrm{C}$. Five series of $30-\mu \mathrm{m}$ coronal SCN sections were prepared on a cryostat and collected in Phosphate-Buffered Saline $(0.1 \mathrm{M}$ PBS, $1 \times)$ and washed with $1 \times$ Tris Buffer Saline pH $7.6(0.1$ M TBS $1 \times)$. Then, sections were incubated in $3 \% \mathrm{H}_{2} \mathrm{O}_{2}$ in TBS (30 min) to suppress endogenous peroxidase activity, thereby reducing background staining. Again brain sections were rinsed in TBS $1 \times$. Brain sections were then transferred in a solution containing $10 \%$ normal serum (either goat or horse according to the host species of the primary antibody) and Triton X-100 $(0.1 \%)$ in TBS for $2 \mathrm{~h}$, followed by incubation in the primary antibody $\left(48 \mathrm{~h}\right.$ at $\left.4^{\circ} \mathrm{C}\right)$. We used rabbit polyclonal anti arginine-vasopressin (AVP) (1:20000, Truus, a gift from Dr. Ruud Buijs, Netherlands Institute for Brain Research, Amsterdam, the Netherlands), goat polyclonal anti-PER1 (1:750; SC7724, Santa Cruz Biotechnologies, Santa Cruz, CA, USA) and rabbit polyclonal anti-PER2 (1:3000, \#PER21A; Alpha Diagnostic International, San Antonio TX, USA; note that for anti-PER2 immunohistochemistry, PBS indicated below was always replaced with TBS). The sections were washed in PBS $1 \times$, then incubated $\left(2 \mathrm{~h}\right.$ at $\left.4^{\circ} \mathrm{C}\right)$ with biotinylated goat antirabbit IgG (1:500, PK6101; Vectastain Standard Elite ABC Kit Vector Laboratories, Inc., Burlingame, CA, USA) for AVP and PER2 and with biotinylated antigoat IgG made in horse (1:500, BA-9500; Vector labs) for PER1 immunostaining. After this, sections were rinsed in PBS $1 \times$ and incubated $(2 \mathrm{~h})$ in a solution containing avidin-biotin peroxidase complex (Vectastain Elite ABC kit; Vector Laboratories Inc.). Following incubation with $\mathrm{ABC}$ reagents, sections were rinsed 4 times in PBS, and incubated with $\mathrm{H}_{2} \mathrm{O}_{2}(0.015 \%$, Sigma-Aldrich, St Louis, MO, USA) and 3,3'-diaminobenzidine tetrahydrochloride (0.5 $\mathrm{mg} / \mathrm{ml}$, Sigma-Aldrich) diluted in water. Thereafter, sections were rinsed with PBS, wet mounted on slides coated with gelatin, dehydrated through a series of alcohols, soaked in xylene, and cover slipped. Photomicrographs were taken on Leica DMRB microscope (Leica Microsystems) with an Olympus DP50 digital camera (Olympus France). The number of immunopositive cells was counted on one section in both SCN's and averaged. 
mRNA extraction and quantitative real-time $P C R$

RNA was extracted from frozen liver samples by homogenizing liver samples in lysis buffer supplemen255 ted with $\beta$-mercaptoethanol and using absolutely RNA miniprep kit (Agilent Technologies, USA. The samples were purified by precipitation with sodium acetate and isopropyl alcohol. The quality of RNA was measured on NanoDrop ND-100 spectrophotometer 260 (NanoDrop Technologies, Wilmington, DE, USA; A260/A280, and A260/A230 values were > 1.8) RNA integrity was assessed using (Agilent RNA 6000 Nano Kit) on Aligent 2100 bio-analyzer for all the liver samples (RIN Value were $>7$ ) bio-analyzer. cDNA 265 was synthesized with the High Capacity RNA to cDNA kit (Applied Biosystem, Foster city CA, USA) using $1 \mu \mathrm{g}$ of RNA. Measurement of relative abundance was performed by real-time PCR analysis using $1 \times$ of TaqMan Gene Expression Master Mix 270 (Life Technologies, Foster city, CA, USA). The following TaqMan probes (Per2: Mm00478113_m1, Clock: Mm00455950_m1, Sirt1: Mm00490758_m1, Fgf21: Mm00840165_g1, Nr1d1 (Rev-erb $\alpha$ ): Mm00520708_m1, Ppara: Mm01208835 m1 and

$275 \operatorname{Pgc}-1 \alpha$ : Mm00440939_m1) were used for all the genes with $1 \mu \mathrm{l}$ of cDNA in the reaction mixture of $20 \mu \mathrm{l}$. Each reaction PCR was done in duplicate. A dilution curve was prepared of pooled cDNA samples using $\log 10$ standards to calculate the amplification 280 efficiency for each primer set (values were between 1.85-1.99). Data were normalized to Tbp (Mm00446971_m1) and analysed the comparative cycle threshold (Ct) method RQ $=2-\Delta \Delta \mathrm{Ct} . \Delta \Delta \mathrm{Ct}=$ $\Delta$ Ct sample $-\Delta$ Ct reference (Pfaffl, 2001) with effi285 ciency corrections. Transcript levels were calculated relative to the mean of $\mathrm{ZT} 0$ samples.

\section{Plasma metabolic parameters}

Plasma samples were obtained after centrifugation of fresh blood collected with 4\% EDTA (10

$290 \mu \mathrm{L}$ for $1 \mathrm{~mL}$ of blood) and centrifuged for 10 min $\left(5000 \mathrm{rpm}\right.$ at $\left.4^{\circ} \mathrm{C}\right)$. Plasma glucose was evaluated with GOD-PAP kit (Biolabo, Maizy, France). The ACS-ACOD method (NEFA-HR2; Wako, Osaka, Japan) was used for assaying 295 plasma non-esterified fatty acids (NEFA). Plasma concentrations of corticosterone were determined by a Rat/Mouse Corticosterone EIA kit (AC-14F1, IDS EURL, Paris, FRANCE). The limit of sensitivity of the assay was $0.55 \mathrm{ng} / \mathrm{mL}$.

\section{Hepatic glycogen assay}

Samples of fresh liver were flash-frozen in liquid nitrogen. Hepatic glycogen was quantified according to the method developed by Murat and Serfaty (Murat \& Serfaty, 1974).

\section{Statistical analysis}

Data are presented as mean \pm standard error of the mean (SEM). Statistical analysis was performed by SigmaPlot (version 12, SPSS Inc, Chicago, IL, USA). Significance was defined at $p<0.05$.

Two-way analysis of variance (ANOVA) with or without repeated measures (RM) were performed to assess the effect of Feeding conditions (food ad libitum, ultradian iso- or ultradian hypo-caloric feeding) and the effect of Time (either baseline versus experimental condition, or time of day), and the Interaction between these factors. Oneway analysis of variance (ANOVA) was performed to assess the effect of Time in the separate feeding groups. When appropriate, post-hoc analysis was performed using Fisher LSD method. For assessing daily rhythmicity, we used a cosinor analysis to determine mean level, amplitude and acrophase of the considered parameter with SigmaPlot software (Jandel Scientific,Chicago, IL). Data were fitted to the following regression: $[y=A+B \cdot \cos (2 \pi(x-C) /$ $24)$ ], where $A$ is the mean level, $B$ the amplitude and $C$ the acrophase of the rhythm.

\section{Results}

\section{Food intake}

When mice were fed with 6 meals of $1 \mathrm{~h}$ each, they ate most of their food during their active period (night time) and less during their resting period $(p<0.001)$. Post-hoc analysis showed a significant effect of Time (night vs. day; Fisher LSD test, $p<0.05$ ) (Figure 1A). Mice on the 15-min 6-meals-a-day feeding schedule, both the hypocaloric and isocaloric group, ate equal amounts of food during day and night. However, the amount of food ingested by the hypocaloric group was significantly lower $(\sim 20 \%)$ than that by the 
340 isocaloric mice, both during day and night (Group: isocaloric vs. hypocaloric, $p<0.001$; Time: night vs. day, $p=0.056$; Interaction: $p=0.88$ ) (Figure $1 \mathrm{~B}$ ). Activity levels being similar in both groups (see below), the reduced food intake and larger loss of body mass in the hypocaloric group seem to be due to a poorer adaptation of these mice to six 10-min meals schedule per day (e.g. less efficient feeding strategy or capacity) compared to isocaloric mice.

\section{Behavioral and physiological outputs of the central clock}

\section{Wheel-running activity}

Two-way ANOVA-RM revealed that during the 6 meals-a-day feeding schedule, daytime activity was more enhanced in hypocaloric animals than in isocaloric mice as compared to ad libitum baseline conditions (Feeding: baseline with food ad libitum vs. 6-meal schedule, $p<0.001$; effect of Group: isocaloric vs. hypocaloric, $p<0.001$ and Interaction, $p<0.001$; Figures 2 and $3 \mathrm{~A}$ ). The proportion of nocturnal activity was lower in the 6 meals-a-day as compared to ad libitum feeding conditions, and the decrease during 6-meals feeding was more marked in the hypocaloric group compared to the isocaloric group (Feeding effect: $p<0.001$; Group effect: $p<0.001$ and Interaction: $p<0.001$; Figure $3 \mathrm{~B}$ ). The total wheelrunning activity was increased during ultradian 15min 6-meal feeding as compared to ad libitum baseline conditions (Feeding: baseline with food ad libitum vs. 6-meal schedule, $p<0.001$ ), while there was no difference between the isocaloric and hypocaloric groups (Group: $p=0.27$; Figure $3 \mathrm{C}$ ).
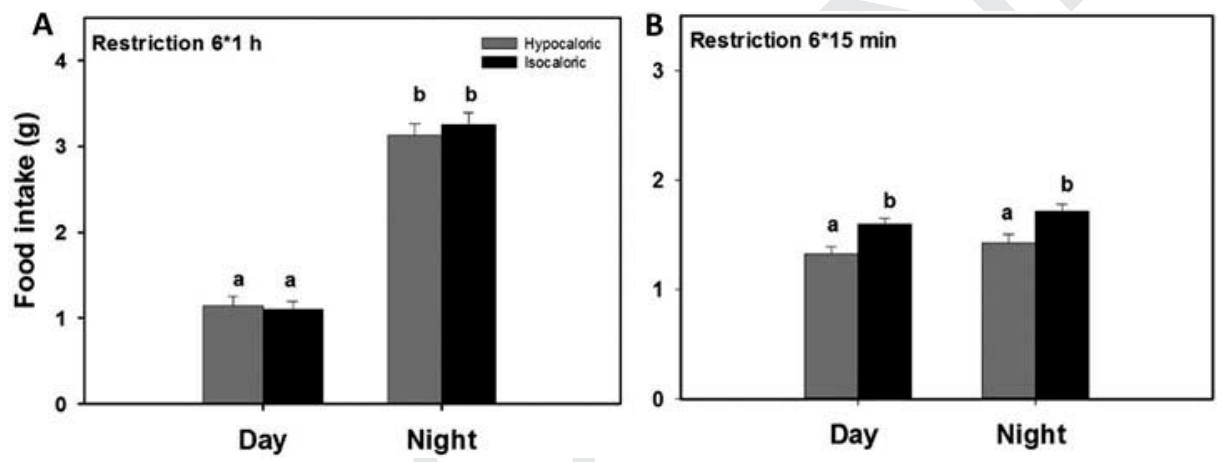

Figure 1. Food intake in mice fed with ultradian 6-meal schedules. (A) Day and night food intake during $6 \times 1$ h ultradian schedules in isocaloric and hypocaloric groups. (B) Day and night food intake during $6 \times 15$ min ultradian schedules for isocaloric and hypocaloric groups. Means ( \pm SEM) lacking common letters are significantly different (Post-hoc test after ANOVA; $p<0.05$ ).
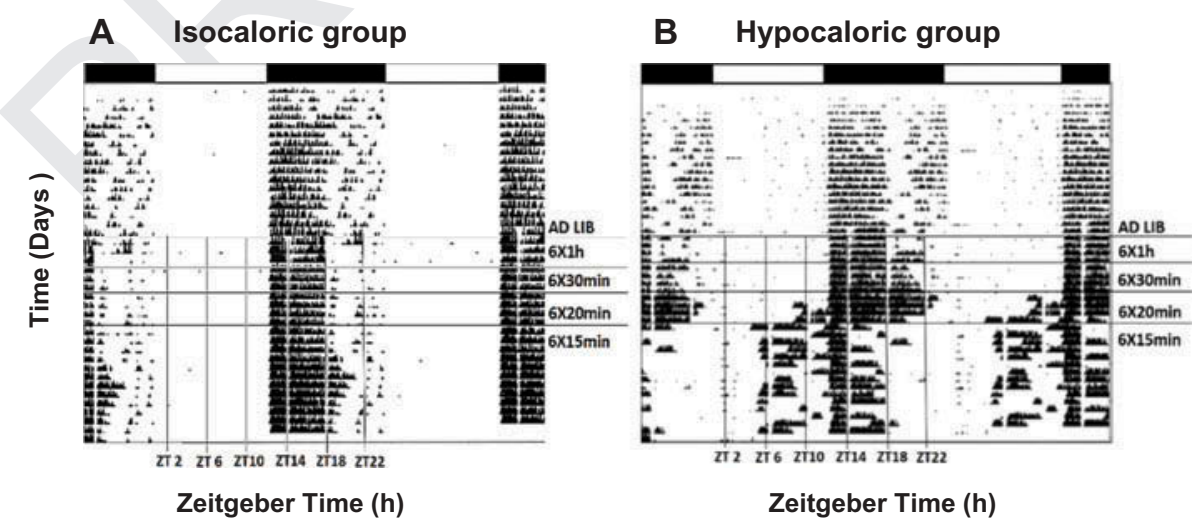

Figure 2. Daily wheel-running activity in two mice submitted to ultradian 6-meal schedules, belonging either to the isocaloric (panel A) or hypocaloric groups (panel B). The horizontal lines show the successive shortening in duration of food access and the vertical lines show the imposed timing of the 6 meals every $4 \mathrm{~h}$, starting at ZT2 (Zeitgeber 2, i.e. $2 \mathrm{~h}$ after lights on). The white area on the 4th day of $6 \times 15$ min feeding schedule is due to a failure in data acquisition ( 12 h). Note the increase in daytime activity, and decrease in nocturnal activity of the mouse of the hypocaloric group (panel B). 

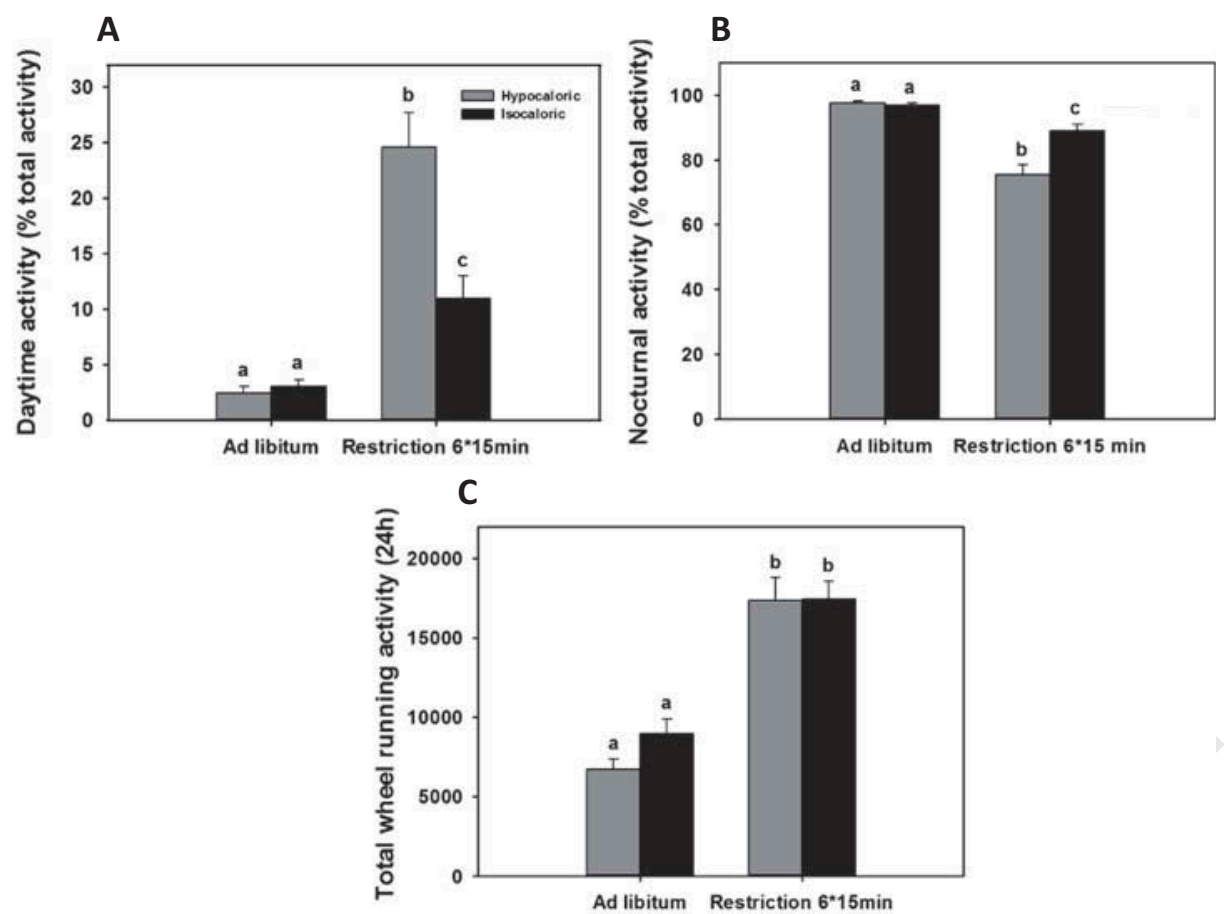

Figure 3. Changes in the levels of wheel-running activity between baseline conditions with with food ad libitum and $6 \times 15$ min ultradian schedules for isocaloric and hypocaloric groups. (A) Daytime wheel-running activity, expressed in \% of the total activity. (B) Nocturnal wheelrunning activity, expressed in \% of the total activity. (C) Total wheel-running activity (per $24 \mathrm{~h}$ ), expressed in numbers of wheel revolutions. Means ( \pm SEM) lacking common letters are significantly different (Post-hoc test after 2-way ANOVA-RM; $p<0.05$ ).

\section{Body temperature}

Two-way ANOVA-RM performed on mean body temperature showed a significant effect of Feeding $(p<0.001)$, a significant effect of Group $(p<0.001)$ and a significant Interaction $(p<0.001)$. Post-hoc analysis (Fisher LSD test, $p<0.05$ ) showed that in mice fed with the ultradian 6-meal schedule mean body temperature decreased with a deeper drop in the hypocaloric group $\left(-1.2^{\circ} \mathrm{C}\right)$ than in the isocaloric group $\left(-0.2^{\circ} \mathrm{C}\right)$, compared to baseline values (Figures 4 and 5A).

The amplitude of the body temperature rhythm was increased by the ultradian 6-meal schedule, both in hypo- or isocaloric conditions (Feeding: $p$ $<0.001$; Group: $p=0.81$; Interaction, $p=0.019$ ) (Figure 5B).

The acrophase of the body temperature rhythm showed a phase-advance during the ultradian 6-meals schedule, with earlier values in the hypocaloric group (i.e. $+3.5 \mathrm{~h}$ compared to baseline peak) compared to the isocaloric group (i.e. $+1.5 \mathrm{~h}$ compared to baseline; Feeding: $p<0.001$; Group: $p<0.006$; and Interaction, $p<0.001$ ) (Figure $5 \mathrm{C}$ ).

\section{Daily expression of clock and clock-controlled proteins in the SCN}

PER1

The expression level of the clock protein PER1 was assessed in the SCN of mice fed ad libitum and in animals fed according the ultradian 6-meal schedule (hypocaloric and isocaloric groups; Figure 6). There were significant effects of Time of day and Feeding, and a significant Interaction between the two parameters $(p<0.001$ for the three factors, Table 1). The significant Feeding effect was caused by a reduction in mean levels of PER1 in the isocaloric and hypocaloric groups, as compared to ad libitum fed controls. One-way ANOVA analysis showed a significant effect of Time in mice fed ad libitum and in the animals fed with ultradian 6-meal schedule (Table 1). Cosinor analysis confirmed the daily rhythmicity of PER1 levels in the SCN of all three groups (peak around ZT14) (Figure 7A, Table 2), as fed with the ultradian 6-meals schedule, with the most reduced levels in the hypocaloric group 

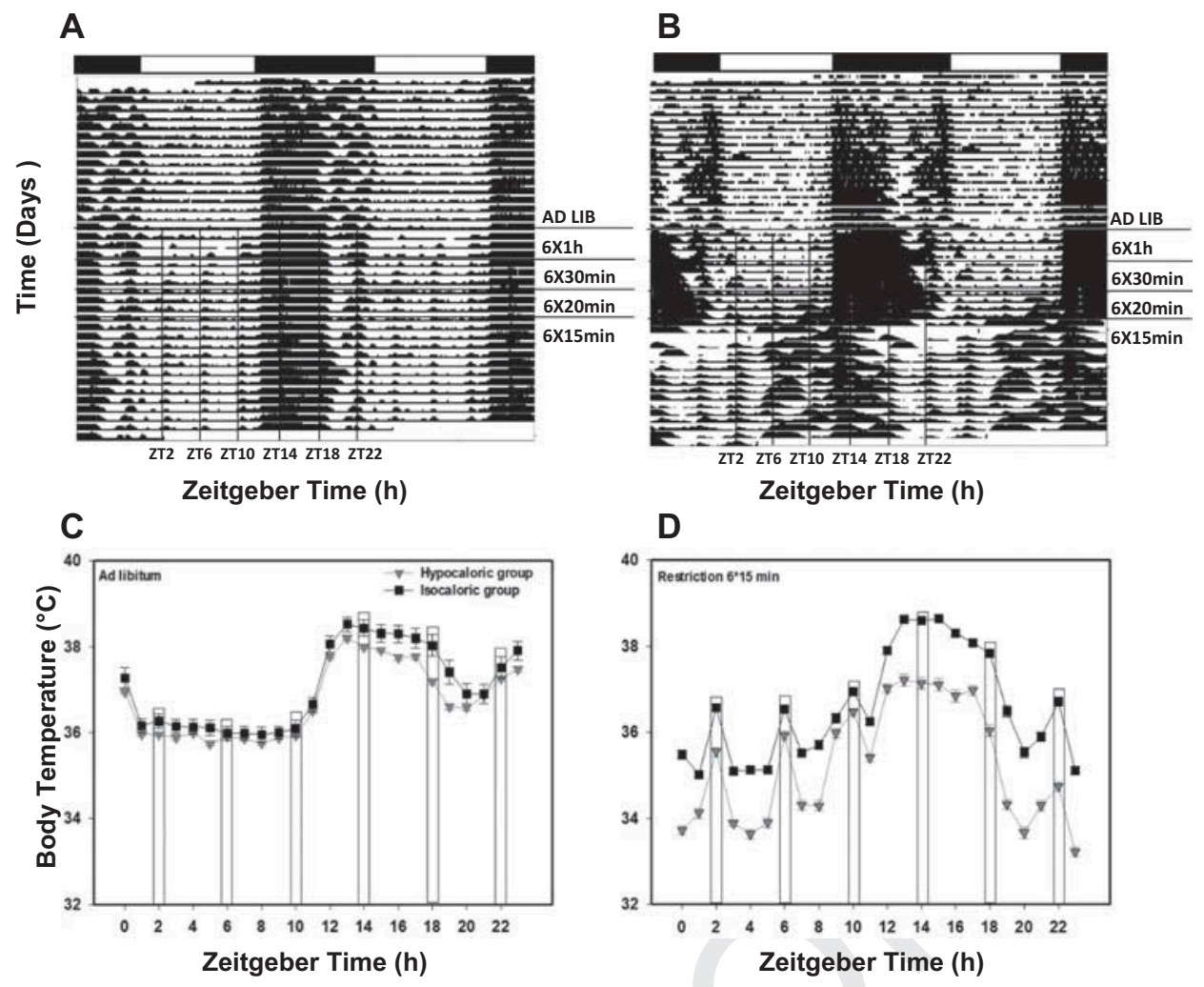

Figure 4. Daily body temperature in two mice submitted to ultradian 6-meal schedules, belonging either to the isocaloric (panel A) or hypocaloric groups (panel B; same mice as in Figure 2). The horizontal lines show the successive shortening in duration of food access and the vertical lines show the imposed timing of the 6 meals every $4 \mathrm{~h}$, starting at ZT2 (Zeitgeber 2, i.e. $2 \mathrm{~h}$ after lights on). The white area on the 4th day of $6 \times 15$ min feeding schedule is due to a failure in data acquisition $(\sim 12 \mathrm{~h})$. Note the increase in daytime thermogenesis, and decrease in nocturnal thermogenesis of the mouse of the hypocaloric group (panel B). The mean daily profiles of body temperature rhythm are during food ad libitum (panel C) and $6 \times 15$ min ultradian schedules (panel D) for isocaloric (black squares) and hypocaloric groups (grey triangles). During 6-meals schedule (panel D) rectangle boxes indicate the time of food access. Note the diet-induced thermogenesis after each meal in panel D. Rectangle boxes are also drawn in panel $\mathrm{C}$ for visual comparison.

(Table 2). In addition, the ultradian 6-meals schedule reduced the amplitude of PER1 expression rhythm in the SCN. Together these results clearly show that the 6 meal feeding conditions affect the master clock.

\section{PER2}

425 Expression of PER2, another core clock protein, was also investigated in the SCN of control mice and those fed according the ultradian 6-meals schedule (Figure 6). Two-way ANOVA revealed significant effects of Time of day and Feeding ( $p$ $430<0.001$ for the two factors Table 1). The One-way ANOVA analysis showed a significant effect of Time in mice fed ad libitum and the animals fed with the ultradian 6-meal schedule (Table 1). Mean levels of PER2 were reduced in both groups of animals fed with the 6-meal schedule, as compared to control mice fed ad libitum (Table 2). Cosinor analysis showed a significant rhythmic expression of PER2 in all three experimental groups, with a peak expression in early night (around ZT13-14) (Figure 7B, Table 2).

\section{Vasopressin (AVP)}

Expression of AVP, a clock-controlled protein, was examined in the SCN of ad libitum fed mice, and animals fed according to the ultradian 6-meal schedule (Figure 6). Two-way ANOVA showed a significant effect of Feeding condition $(p<0.001)$ and a significant Interaction ( $p=0.005$; Table 1$)$. One-way ANOVA analysis showed a significant effect of Time in mice fed ad libitum, but not in animals fed with the ultradian 6-meal schedule the SCN were up-regulated by $30 \%$ throughout the 

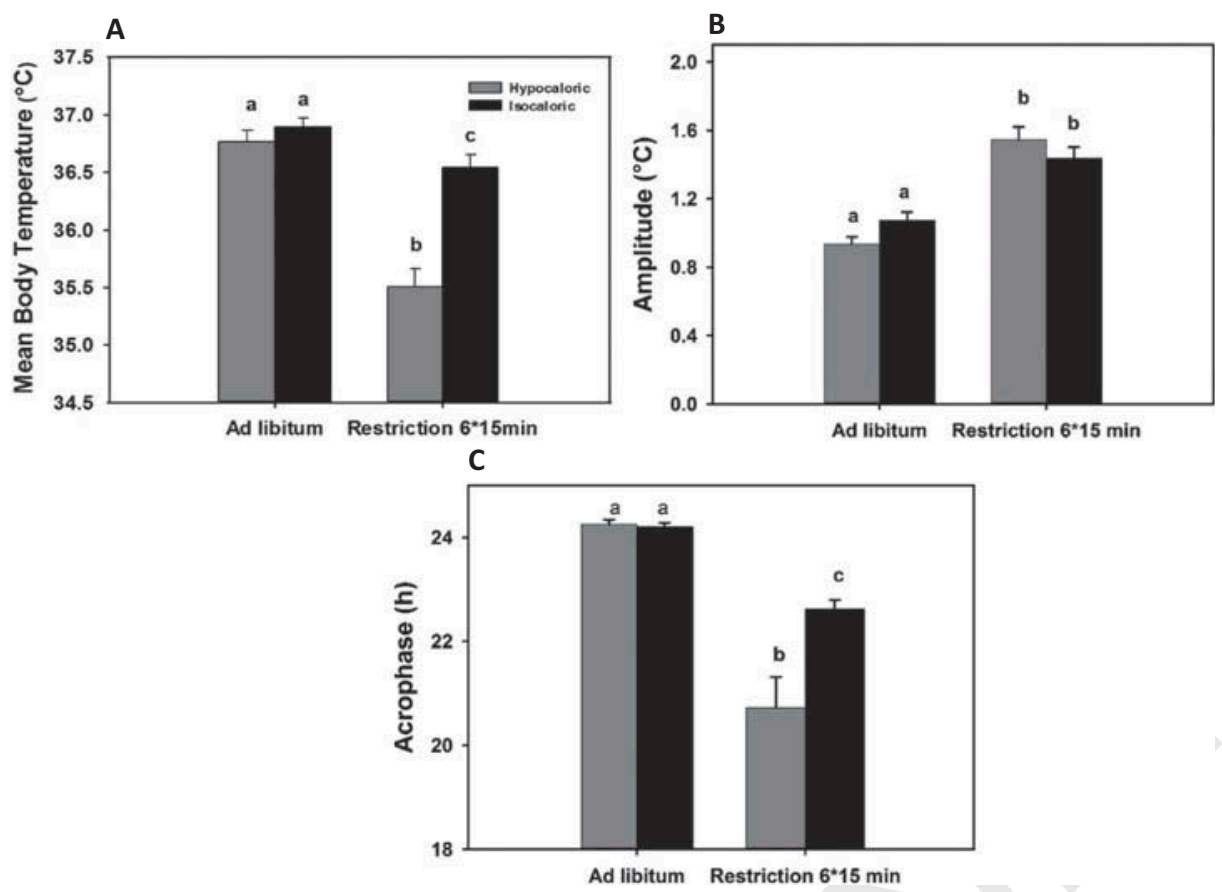

Figure 5. Changes in body temperature between baseline conditions with food ad libitum and $6 \times 15$ min ultradian schedules for isocaloric and hypocaloric groups, including mean body temperature (A), amplitude rhythm (B), and acrophase (C). Means ( \pm SEM) lacking common letters are significantly different (Post-hoc test after 2-way ANOVA-RM; $p<0.05$ ).

$24 \mathrm{~h}$ cycle in both the isocaloric and hypocaloric group, compared to the control group fed ad libitum (Table 2). Cosinor analysis detected a significant rhythm in the ad libitum fed group, with an acrophase at dusk, around ZT11, but not in the isocaloric and hypocaloric groups (Figure 7C, Table 2). The lack of rhythmicity in the isocaloric 6-meals schedule groups indicates that the ultradian feeding schedule may have a major impact on SCN functioning.

\section{Rhythms of plasma metabolites}

\section{Plasma glucose}

465 While the main effect of Time of day was not significant for plasma glucose (Table 1), significant differences among groups did occur (Feeding $(p<0.001)$ and Interaction $(p<0.01))$. The oneway ANOVA analysis showed a significant effect of Time in mice fed ad libitum, but no effect of Time in the animals fed with ultradian 6-meal schedule (Table 1). Cosinor analysis detected a significant rhythm in plasma glucose only in ad libitum group (Table 3). As compared to ad libitum control values, the mean levels of plasma glucose were unchanged and reduced in isocaloric and hypocaloric groups, respectively (Figure 8A, Table 3). These results indicate that the ultradian 6-meal schedule causes arrhythmicity of the plasma glucose rhythm in both the isocaloric and hypocaloric group and an additional hypoglycemia in the hypocaloric group.

\section{Non-esterified fatty acids (NEFA)}

Two-way ANOVA showed a significant effect of Time of Day $(p=0.034)$ and Feeding condition $(p=0.020)$, but no Interaction (Table 1). One-way ANOVA analysis showed a significant effect of Time only in the isocaloric group, but not in the animals fed ad libitum (Table 1). Cosinor analysis showed no significant daily rhythms for plasma NEFA levels (Figure 8B, Table 3).

\section{Plasma corticosterone}

The daily corticosterone rhythm was significantly affected by the different feeding conditions Feeding $(p<0.001)$ and Interaction $(p<0.003$; Table 1$)$. The one-way ANOVA analysis showed a significant effect of Time in all 3 feeding groups (Table 1), as did the cosinor regression (Table 3). Remarkably, the ultradian 6-meal schedule did not modify its basal levels at 


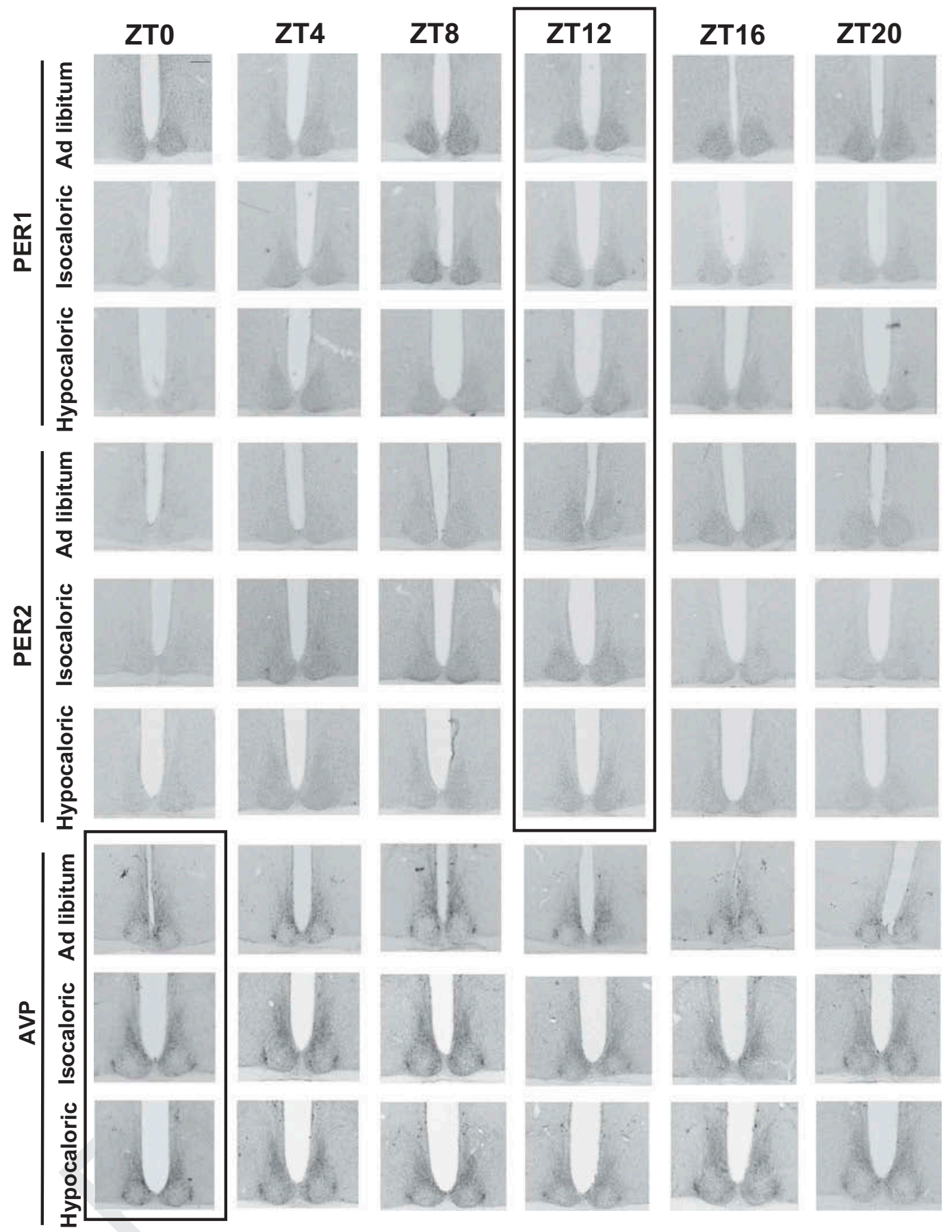

Figure 6. Photomicrographs of PER1, PER2 and AVP immunostaining in the SCN of ad libitum fed, Isocaloric and Hypocaloric groups. Frames indicate the time points with largest differences among groups. Scale bar, $200 \mu \mathrm{m}$. ZT, Zeitgeber time (ZT0 and ZT12 defining lights on and off, respectively).

500 dawn. By contrast, ultradian feeding caused an increase of the daily amplitude of corticosterone variations, especially in the hypocaloric group (Figure 8C, Table 3).

\section{Liver glycogen}

Two-way ANOVA showed significant effects of Time $(p<0.001)$, but not of Feeding or
Interaction (Table 1). One-way ANOVA analysis showed a significant effect of Time in fed ad libitum control, isocaloric and hypocaloric groups (Table 1). Cosinor regression showed a significant rhythm in all 3 groups (Table 3; Figure 8D). Of note, in contrast to plasma glucose, neither the phase, nor the levels of liver glycogen were affected by the ultradian 6-meal feeding. 
Table 1. $p$ values for the effects of time, feeding and interaction (two-way ANOVA) and effect of time for each feeding condition (one-way ANOVA).

\begin{tabular}{|c|c|c|c|c|c|c|}
\hline & \multicolumn{3}{|c|}{ Two-way ANOVA (Time $\times$ Feeding) } & \multicolumn{3}{|c|}{ One-way ANOVA (Time) } \\
\hline & Time & Feeding & Interaction & Ad libitum & Isocaloric & Hypocaloric \\
\hline \multicolumn{7}{|l|}{ Proteins } \\
\hline PER1 & $<0.001$ & $<0.001$ & $<0.001$ & $<0.001$ & $=0.014$ & $=0.031$ \\
\hline PER2 & $<0.001$ & $<0.001$ & $=0.209$ & $<0.001$ & $<0.001$ & $<0.001$ \\
\hline AVP & $=0.247$ & $<0.001$ & $=0.005$ & $=0.007$ & $=0.776$ & $=0.129$ \\
\hline \multicolumn{7}{|c|}{ Plasma metabolites } \\
\hline Glucose & $=0.985$ & $=0.001$ & $=0.008$ & $=0.041$ & $=0.069$ & $=0.500$ \\
\hline NEFA & $=0.034$ & $=0.020$ & $=0.344$ & $=0.795$ & $=0.026$ & $=0.285$ \\
\hline Corticosterone & $<0.001$ & $<0.001$ & $=0.003$ & $<0.001$ & $=0.002$ & $=0.001$ \\
\hline Liver glycogen & $<0.001$ & $=0.229$ & $=0.144$ & $<0.001$ & $=0.004$ & $=0.016$ \\
\hline \multicolumn{7}{|l|}{ Clock genes } \\
\hline Per2 & $<0.001$ & $<0.001$ & $<0.001$ & $<0.001$ & $<0.001$ & $<0.010$ \\
\hline Clock & $<0.001$ & $<0.001$ & $<0.001$ & $<0.001$ & $<0.001$ & $=0.044$ \\
\hline Rev-erba & $<0.001$ & $=0.030$ & $<0.001$ & $<0.001$ & $<0.001$ & $=0.003$ \\
\hline \multicolumn{7}{|l|}{ Metabolic genes } \\
\hline Sirt1 & $<0.001$ & $=0.080$ & $=0.448$ & $=0.151$ & $=0.061$ & $=0.049$ \\
\hline Ppara & $=0.159$ & $=0.002$ & $=0.007$ & $<0.001$ & $=0.002$ & $=0.416$ \\
\hline Pgc-1a & $=0.007$ & $<0.001$ & $=0.162$ & $<0.002$ & $=0.229$ & $=0.176$ \\
\hline Fgf21 & $=0.005$ & $<0.001$ & $=0.017$ & $=0.076$ & $=0.293$ & $=0.015$ \\
\hline
\end{tabular}
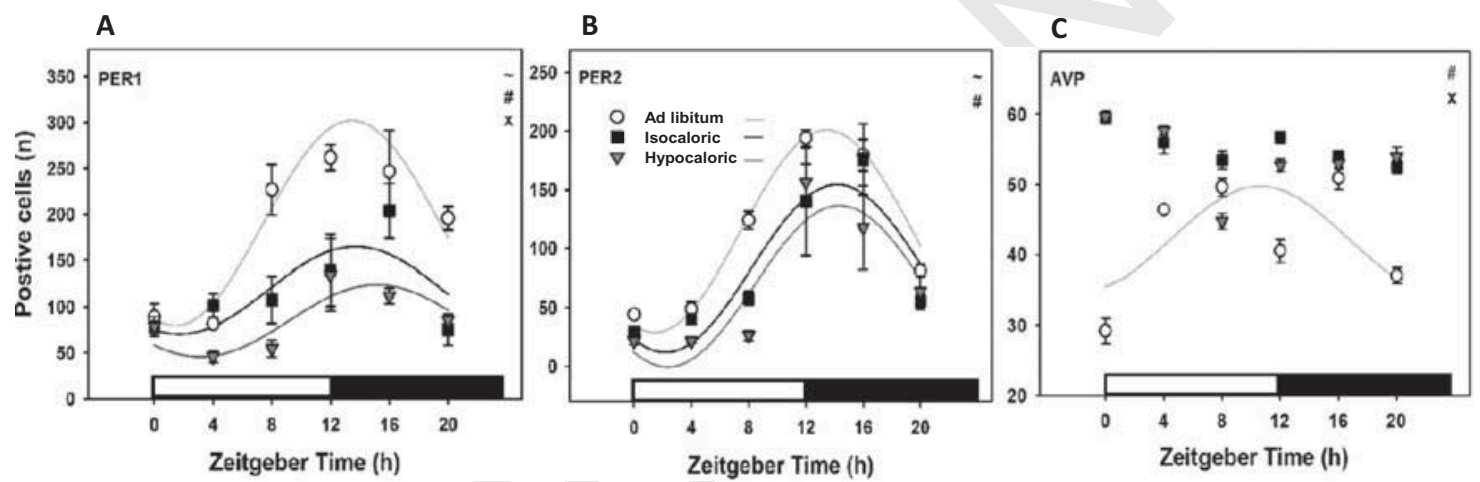

Figure 7. Daily profiles of expression of clock and clock-controlled proteins in the SCN of fed ad libitum (white circle), ultradian isocaloric (black square) and hypocaloric (dark grey triangle) groups. (A) PER1 expression; (B) PER2 expression; (C) AVP expression. Fitted lines show significant cosine regressions (see methods). effect of time of day $(p<0.05)$, \# effect of feeding $(p<0.05)$ and $\times$ interaction between feeding and time of day $(p<0.05)$.

Table 2. Parameters of cosinor regressions of daily expression of clock and clock-controlled proteins in the SCN.

\begin{tabular}{|c|c|c|c|c|c|c|c|c|c|c|}
\hline & & \multicolumn{3}{|c|}{ SCN PER1 ( $n$ cells) } & \multicolumn{3}{|c|}{ SCN PER2 ( $n$ cells) } & \multicolumn{3}{|c|}{ SCN AVP ( $n$ cells) } \\
\hline & & Mean & SEM & $p$ & Mean & SEM & $p$ & Mean & SEM & $p$ \\
\hline \multirow[t]{3}{*}{ Ad libitum $(n=30)$} & $\mathrm{a}$ & $\overline{191.06^{*}}$ & 9.17 & $<0.001$ & $114.92^{*}$ & 3.81 & $<0.001$ & $42.43^{\#}$ & $1.92^{*}$ & $=0.040$ \\
\hline & b & $111.14^{*}$ & 13.03 & & 85.96 & 5.40 & & 7.32 & 2.70 & \\
\hline & c & 13.43 & 0.44 & & 13.44 & 0.23 & & 10.60 & 1.42 & \\
\hline \multirow[t]{3}{*}{ Isocaloric $(n=24)$} & $\mathrm{a}$ & $117.79^{\wedge}$ & 11.08 & $<0.001$ & 83.79 & 8.53 & $<0.001$ & 55.37 & 1.45 & $=0.799$ \\
\hline & $b$ & 47.27 & 15.67 & & 70.08 & 11.75 & & - & - & \\
\hline & c & 13.69 & 1.26 & & 14.22 & 0.67 & & - & - & \\
\hline \multirow[t]{3}{*}{ Hypocaloric $(n=22)$} & $\mathrm{a}$ & 84.93 & 8.04 & $<0.001$ & 68.00 & 7.61 & $<0.001$ & 53.56 & 1.57 & $=0.135$ \\
\hline & $b$ & 39.18 & 11.58 & & 68.48 & 10.99 & & - & - & \\
\hline & c & 15.14 & 1.08 & & 14.34 & 0.58 & & - & - & \\
\hline
\end{tabular}

Table 2 shows the three parameters of cosinor regressions, including a) the mean level, b) the amplitude, and c) the acrophase of the rhythm (see Methods for details). For the acrophase, the reference time is Zeitgeber 0 (i.e., lights on).* Ad libitum group is significantly different from Isocaloric and Hypocaloric groups $(p<0.05)$. Isocaloric group is significantly different from Hypocaloric group $(p<0.05)$. ${ }^{\#} A d$ libitum group is significantly different from Hypocaloric group $(p<0.05)$. $P$ values in the right columns indicate the significance of the cosinor fit. 
Table 3. Parameters of cosinor regressions of daily variations of plasma glucose, non-esterified fatty acids, liver glycogen, and plasma corticosterone.

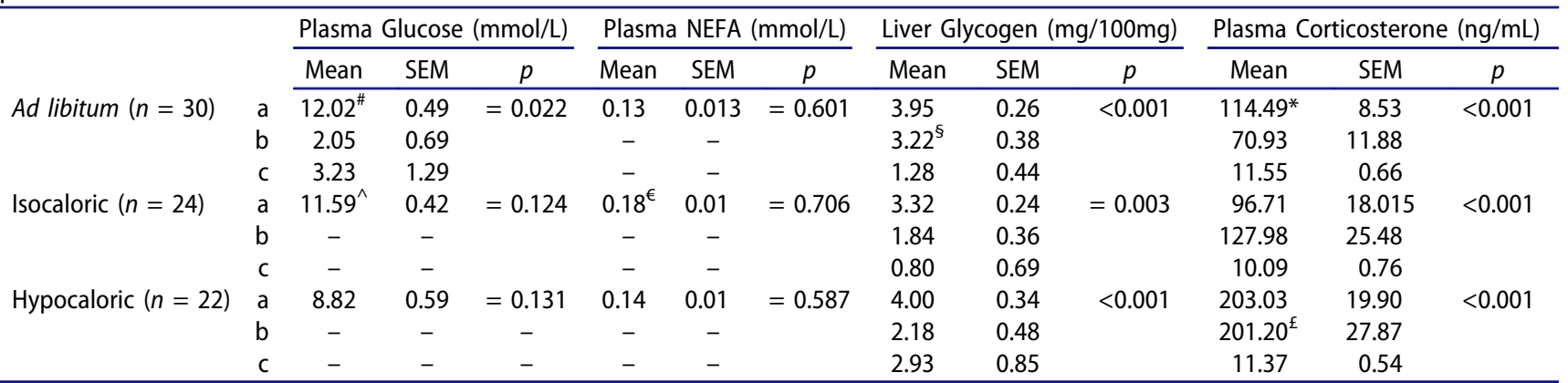

Table 3 shows the three parameters of cosinor regressions, including a) the mean level, b) the amplitude, and c) the acrophase of the rhythm (see Methods for details). For the acrophase, the reference time is Zeitgeber 0 (i.e., lights on). ${ }^{*}$ Ad libitum group is significantly different from Isocaloric and Hypocaloric groups $(p<0.05)$. 'Isocaloric group is significantly different from Hypocaloric group $(p<0.05)$. ${ }^{\#} A d$ libitum group is significantly different from Hypocaloric group $(p<0.05) .{ }^{⿷}$ Hypocaloric group is different from Isocaloric and Ad libitum fed groups $(p<0.05) .{ }^{\S}$ Ad libitum group is different from Isocaloric group $(p<0.05){ }^{€}$ Isocaloric is different from Ad libitum. NEFA, non-esterified fatty acids and glucose mmol/L, Millimoles per Litre. Liver glycogen $\mathrm{mg} / 100 \mathrm{mg}$, Milligram of glycogen per 100 milligrams of liver. Plasma corticosterone $\mathrm{ng} / \mathrm{ml}$, Nanogram per Milliliter. $p$ values on the right columns indicate significance of the cosinor fit. Non-significant parameters are not shown (-).

A

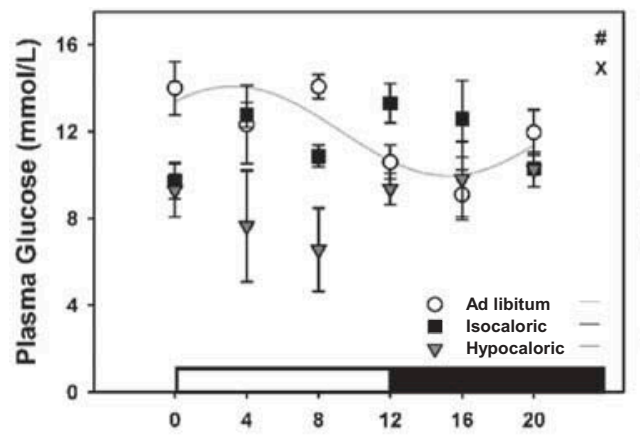

C

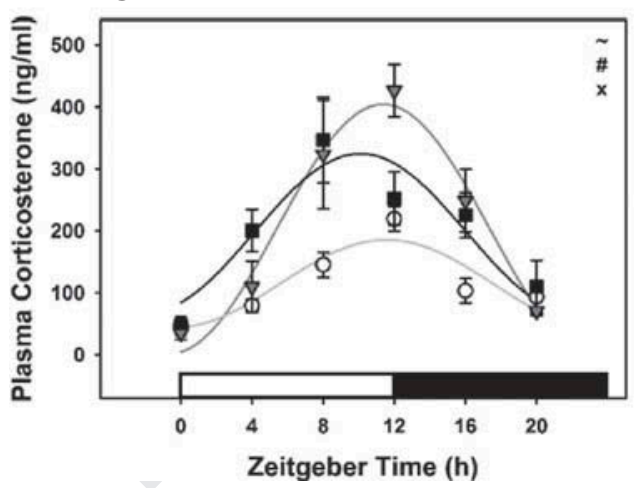

B
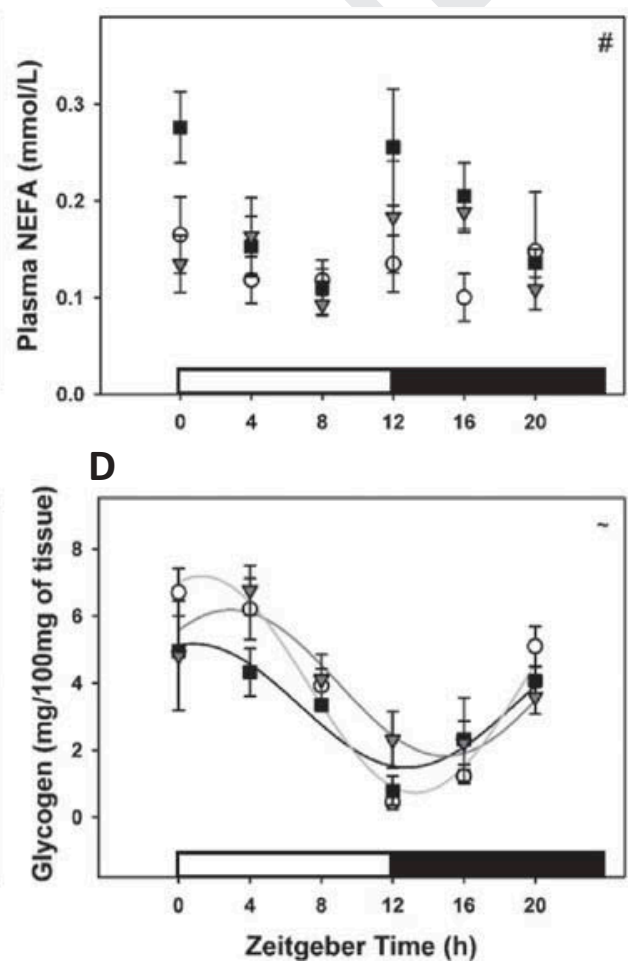

Figure 8. Daily profiles of plasma glucose, non-esterified fatty acids, corticosterone, and hepatic glycogen in fed ad libitum (white circle), ultradian isocaloric (black square) and hypocaloric (dark grey triangle) groups. (A) Plasma glucose, (B) Plasma non-esterified fatty acids (NEFA) (C) Plasma corticosterone (D) Hepatic glycogen. Fitted lines show significant cosine regressions (see methods). effect of time of day $(p<0.05)$, \# effect of feeding $(p<0.05)$ and $x$ interaction between feeding and time of day $(p<0.05)$.

\section{Daily expression of clock and metabolic genes in the liver}

\section{Per2}

The one-way ANOVA analysis showed a significant effect of Time in all 3 feeding groups (Table 1) and so did the cosinor regressions
(Table 4). However, the significant effects of Feeding $(p<0.001)$ and Interaction $(p<0.001)$; Table 1) indicate that these rhythms differed between groups. Indeed, Per 2 expression was down-regulated and markedly phase-advanced by the ultradian 6-meal feeding in both hypocaloric 
(7 h) and isocaloric groups (4 h), as compared to control mice fed ad libitum (Figure 9A, Table 4).

\section{Clock}

530 Expression of the circadian gene Clock in the liver was still rhythmic in mice fed according to the ultradian 6-meal schedule (Time of day, $p<0.001$; Tables 1 and 4). The significant effects of Feeding ( $p$ $<0.001)$ and Interaction $(p<0.001)$ indicated a down-regulated Clock expression only in isocaloric 6-meal fed mice (Figure 9B, Tables 1 and 4). Moreover, hepatic expression of Clock was phaseadvanced, respectively, by 3.5 and $1.2 \mathrm{~h}$ in the isocaloric and hypocaloric groups, as compared to control mice fed ad libitum (Figure 9B, Table 4)

\section{Rev-erba}

The hepatic expression of Rev-erb $\alpha$ (also known as Nr1d1) showed rhythmic expression for all feeding conditions (Time of day, $p<0.001$; Feeding $(p=0.03$ ) and Interaction ( $p<0.001)$; Tables 1 and 4$)$. Rev-erb $\alpha$ expression was phase-advanced, respectively, by $\sim 3.5$ and $4.7 \mathrm{~h}$ in the hypocaloric and isocaloric groups, as compared to control mice fed ad libitum (Figure 9C, Table 4).

\section{Sirt1}

Two-way ANOVA showed a significant effect of Time for Sirt1 expression in the liver $(p<0.001$; Table 1), but no effect of Feeding or Interaction. One-way ANOVA analysis showed a significant mice but not in the mice fed ad libitum or the isocaloric group (Table 1). Cosinor regression showed a significant rhythm in ad libitum and

hypocaloric groups (Table 5). Sirt1 expression was not significantly phase-shifted in mice fed with the ultradian 6-meal schedule, as compared to control mice fed ad libitum (Figure 9D, Table 5).

\section{Ppara}

The expression of the metabolic gene peroxisomeproliferative-activated-receptor alpha $(P p a r \alpha)$ in the liver was rhythmic only in the isocaloric group and the ad libitum fed animals as indicated by the one-way ANOVA (Table 1). Moreover there was a significant effect of Feeding $(p<0.002)$ and Interaction $(p<0.007)$ (Table 1$)$. Cosinor regression indicated significant rhythms in the ad libitum and isocaloric groups (Table 5). Ppara expression was down-regulated in isocaloric 6-meal fed group (Figure 9E, Table 5).

\section{Pgc-1a}

The hepatic expression of $P g c-1 \alpha$ showed significant effects of Time ( $p=0.007$; Table 1) and Feeding $(p<0.001)$. The effect of Feeding was caused by the up-regulated $P g c-1 \alpha$ expression during ultradian 6-meal feeding, especially in the hypocaloric group, as compared to control mice fed ad libitum (Figure 9F, Table 1). One-way ANOVA analysis showed a significant effect of Time only in the mice fed ad libitum, but not in the animals fed with ultradian 6-meal schedule (Table 1) and significant cosinor regressions in all the groups (Table 5).

\section{Fgf21}

The significant effect of Feeding $(p<0.001)$ and Interaction $(p=0.017)$ was caused by $F g f 21$

Table 4. Parameters of cosinor regressions of daily expression of clock genes in the liver.

\begin{tabular}{|c|c|c|c|c|c|c|c|c|c|c|}
\hline & & \multicolumn{3}{|c|}{ Liver Per2 (a.u.) } & \multicolumn{3}{|c|}{ Liver Clock (a.u.) } & \multicolumn{3}{|c|}{ Liver Clock (a.u.) } \\
\hline & & Mean & SEM & $p$ & Mean & SEM & $p$ & Mean & SEM & $p$ \\
\hline \multirow{3}{*}{ Ad libitum $(n=30)$} & $\mathrm{a}$ & $2.18^{*}$ & 0.11 & $<0.001$ & $0.76^{\S}$ & 0.02 & $<0.001$ & 9.51 & 1.24 & $<0.001$ \\
\hline & $\mathrm{b}$ & $2.09^{*}$ & 0.16 & & 0.30 & 0.03 & & 13.40 & 1.81 & \\
\hline & C & $15.75^{*}$ & 0.28 & & $22.66^{*}$ & 0.45 & & $7.10^{*}$ & 0.49 & \\
\hline \multirow[t]{3}{*}{ Isocaloric $(n=24)$} & $\mathrm{a}$ & 1.41 & 0.14 & $<0.001$ & $0.55^{\wedge}$ & 0.02 & $<0.001$ & 6.53 & 0.99 & $<0.001$ \\
\hline & $\mathrm{b}$ & 1.06 & 0.20 & & 0.21 & 0.03 & & 8.37 & 1.40 & \\
\hline & c & $11.81^{\wedge}$ & 0.71 & & $19.19^{\wedge}$ & 0.59 & & 3.56 & 0.64 & \\
\hline \multirow[t]{3}{*}{ Hypocaloric $(n=22)$} & a & 1.70 & 0.17 & $<0.001$ & 0.75 & 0.03 & $=0.004$ & 9.47 & 1.35 & $<0.001$ \\
\hline & $\mathrm{b}$ & 1.08 & 0.24 & & 0.21 & 0.05 & & 9.60 & 1.95 & \\
\hline & C & 8.71 & 1.88 & & 21.42 & 0.99 & & 2.37 & 0.74 & \\
\hline
\end{tabular}

Table 4 shows the three parameters of cosinor regressions, including a) the mean level, b) the amplitude, and c) the acrophase of the rhythm (see Methods for details). For the acrophase, the reference time is Zeitgeber 0 (i.e., lights on). ${ }^{*}$ Ad libitum group is significantly different from Isocaloric and Hypocaloric groups $(p<0.05)$. Isocaloric group is significantly different from Hypocaloric group $(p<0.05) .{ }^{\S} A d$ libitum group is different from Isocaloric group $(p<0.05)$. a.u., arbitrary units. $\mathrm{P}$ values on the right columns indicate significance of the cosinor analysis. 

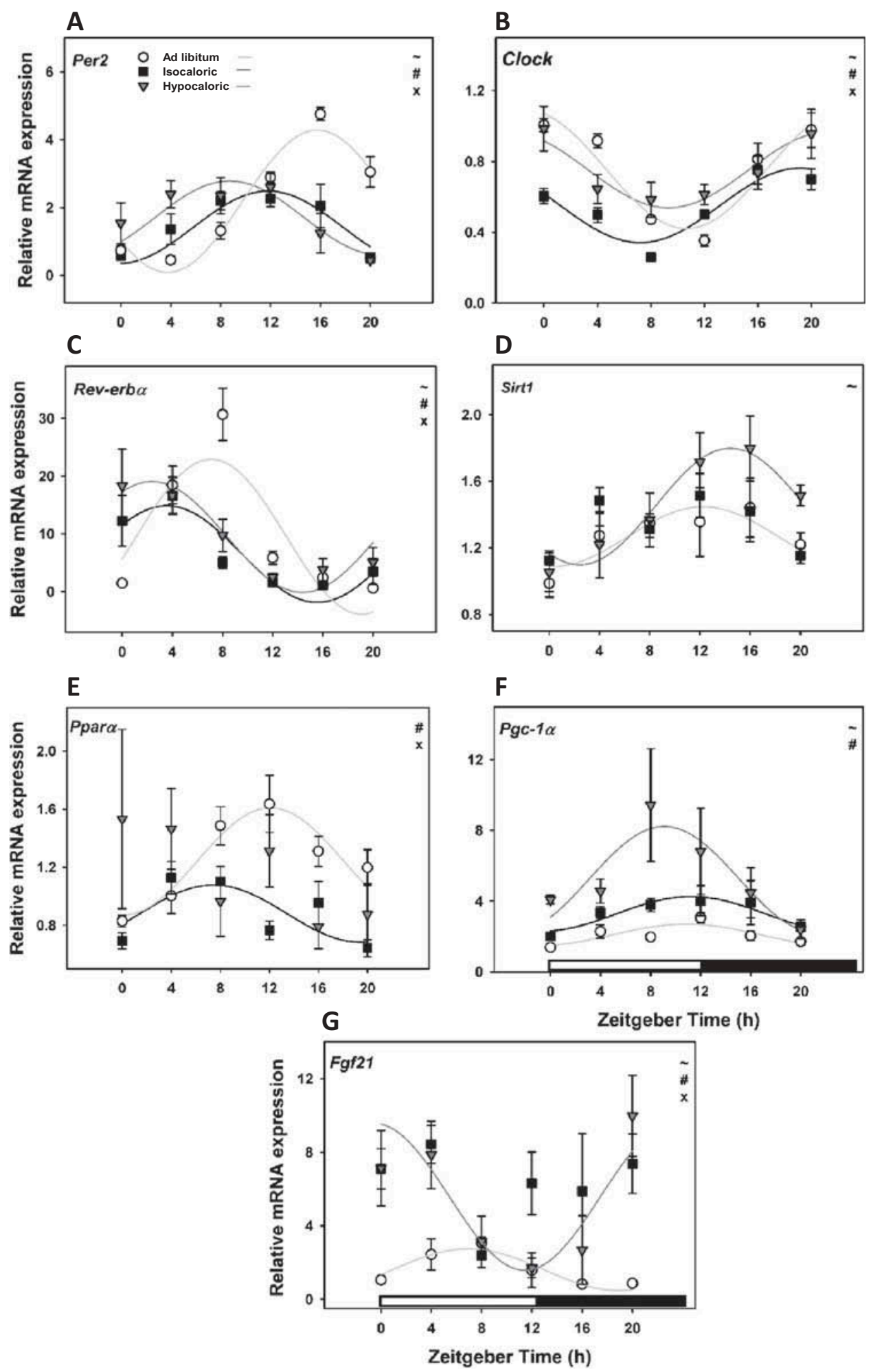

Figure 9. Daily profiles of hepatic expression of clock and metabolic genes in fed ad libitum (white circle), ultradian isocaloric (black square) and hypocaloric (dark grey triangle) groups. (A) Per2, (B) Clock, (C) Rev-erba, (D) Sirt1, (E) Ppara, (F) Pgc-1a and (G) Fgf21. Fitted lines show significant cosine regressions (see methods). effect of time of day $(p<0.05)$, \# effect of feeding $(p<0.05)$ and $\mathrm{x}$ interaction between feeding and time of day $(p<0.05)$. 
Table 5. Parameters of cosinor regressions of daily expression of metabolic genes in the liver.

\begin{tabular}{|c|c|c|c|c|c|c|c|c|c|c|c|c|c|}
\hline & & \multicolumn{3}{|c|}{ Liver Sirt1 (a.u.) } & \multicolumn{3}{|c|}{ Liver Ppara (а.u.) } & \multicolumn{3}{|c|}{ Liver Pgc-1a (a.u.) } & \multicolumn{3}{|c|}{ Liver Fgf21 (а.u.) } \\
\hline & & Mean & SEM & $p$ & Mean & SEM & $p$ & Mean & SEM & $p$ & Mean & SEM & $p$ \\
\hline \multirow[t]{3}{*}{ Ad libitum $(n=30)$} & $a$ & 1.27 & 0.05 & $=0.050$ & $1.24^{\S}$ & 0.05 & $<0.001$ & $2.08^{*}$ & 0.11 & $=0.002$ & 1.61 & 0.23 & $=0.009$ \\
\hline & $b$ & 0.18 & 0.07 & & 0.37 & 0.07 & & 0.61 & 0.16 & & $1.13^{\#}$ & 0.33 & \\
\hline & c & 12.23 & 1.55 & & $12.09^{\S}$ & 0.76 & & 10.88 & 1.01 & & $6.93^{\#}$ & 0.65 & \\
\hline \multirow[t]{3}{*}{ Isocaloric $(n=24)$} & $\mathrm{a}$ & 1.33 & 0.04 & $=0.066$ & 0.88 & 0.04 & $=0.015$ & $3.27^{\wedge}$ & 0.26 & $=0.042$ & $6.14^{\epsilon}$ & 0.74 & $=0.326$ \\
\hline & $b$ & - & - & & 0.20 & 0.06 & & 0.98 & 0.36 & & - & - & \\
\hline & c & - & - & & 7.43 & 1.20 & & 11.23 & 1.4 & & - & - & \\
\hline \multirow[t]{3}{*}{ Hypocaloric $(n=22)$} & $a$ & 1.45 & 0.06 & $=0.003$ & 1.15 & 0.12 & $=0.364$ & 5.25 & 0.75 & $=0.033$ & $5.57^{*}$ & 0.71 & $=0.003$ \\
\hline & $b$ & 0.35 & 0.09 & & - & - & & $2.97^{f}$ & 1.04 & & 3.99 & 1.01 & \\
\hline & c & 14.41 & 0.94 & & - & - & & 9.09 & 1.39 & & 23.44 & 0.95 & \\
\hline
\end{tabular}

Table 5 shows the three parameters of cosinor regressions, including a) the mean level, b) the amplitude, and c) the acrophase of the rhythm (see Methods for details). For the acrophase, the reference time is Zeitgeber 0 (i.e., lights on). ${ }^{*}$ Ad libitum group is significantly different from Isocaloric and Hypocaloric groups $(p<0.05)$. Isocaloric group is significantly different from Hypocaloric group $(p<0.05)$. ${ }^{\#} A d$ libitum group is significantly different from Hypocaloric group $(p<0.05)$. ${ }^{\S}$ Ad libitum group is different from Isocaloric group $(p<0.05)$. $£$ Hypocaloric group is different from Isocaloric and $A d$ libitum fed groups $(p<0.05)$. ${ }^{€}$ Isocaloric is different from Ad libitum. ${ }^{¥}$ Hypocaloric is different from Ad libitum. a.u., arbitrary units. $p$ values on the right columns indicate significance of the cosinor analysis. Non-significant parameters are not shown (-).

expression being up-regulated by the ultradian 6-meal schedule (Figure 9G, Table 1). Fgf21 in liver showed rhythmic expression in ad libitum and hypocaloric group (Table 5). One-way 595 ANOVA analysis showed a significant effect of Time only in hypocaloric group of mice fed under ultradian 6 meal schedule (Table 1).

\section{Discussion}

Challenging mice with a 6-meals-a-day feeding running activity, thereby leading to a more diurnal phenotype in locomotor activity. Hence we concluded that ultradian periodicity of the meals and hypocaloric condition cause significant changes in the SCN and peripheral clocks, and that metabolic cues associated with caloric restriction modulate the temporal niche of activity.

\section{Physiological and behavioural changes}

Mice fed according to the ultradian feeding schedule were initially given food access for $1 \mathrm{~h}$ every 4 $\mathrm{h}(6 \times 1 \mathrm{~h}$ per $24 \mathrm{~h})$. During this stage of the 6 meals-a-day feeding protocol, animals show a normal pattern of food intake characterized by high nocturnal intake, but when each food access was shortened to $15 \mathrm{~min}(6 \times 15 \mathrm{~min}$ per $24 \mathrm{~h})$ the mice eat equal amounts of food during day and night. Similar adaptations to such unusual feeding schedules have been initially demonstrated in rats fed with an ultradian 6-meals schedule of $6 \times 10$ min each (Kalsbeek \& Strubbe, 1998). More recently, another team applied this protocol in mice (Kuroda et al., 2012). In the present study, the fact that about half of the mice on the ultradian feeding schedule lost body mass led us to subdivide them into two groups, isocaloric and hypocaloric mice (with a cut-off for $10 \%$ of body mass loss). The similar levels of wheel-running activity between the two groups indicate that the differences observed in the hypocaloric group are likely due to reduced energy intake and related metabolic changes.

While the isocaloric group of mice maintained essentially a nocturnal pattern of wheel-running activity under the ultradian feeding schedule, the behavioral pattern is very different in the hypocaloric group. These mice became partially diurnal, being inactive during late night and shifting their activity onsets toward daytime. These data suggest that the SCN is affected by hypocaloric feeding. A 
daily hypocaloric single meal has previously been shown to induce phase-advances of the rest-activity rhythm in both rats and mice, independent of the time of hypocaloric feeding (Challet et al., 1997; Challet et al., 1998). Also, energetic constraints associated with the so-called work for food paradigm lead to shifts of the nocturnal 660 activity pattern of mice to diurnality (Hut et al., 2011; van der Vinne et al., 2014). When diurnal grass rats (Arvicanthis ansorgei) are fed with daily hypocaloric feeding at night, they become partially nocturnal (Mendoza et al., 2012). In addition to the dramatic reorganization of rest-activity rhythm in the hypocaloric mice, it is worth mentioning that these mice also display some anticipatory activity prior to food access at ZT6 (Figure 2B) that is not seen in the isocaloric group (Figure 2A).

670 A previous work studied behavioral changes of calorie restricted mice fed with a daily amount equal to $60 \%$ of ad libitum conditions using automatic feeders that delivered food pellets every $4 \mathrm{~h}$. Compared to control mice (i.e. fed ad libitum in 675 addition to the food pellets supplied by the feeders), calorie restricted mice displayed increased daytime activity, as in our hypocaloric group, and anticipation to the meals, especially those occurring during daytime (Luby et al., 2012).

A drop in the mean body temperature was detected when mice were fed according to the ultradian feeding rhythm. Such drops in body temperature are also seen when rats and mice are fasted (Nagashima et al., 2003; Tokizawa et al., 2015) and other conditions with energetic challenges (e.g. Hut et al., 2011), likely helping these animals to minimize their energy expenditure. Previously a drop in mean body temperature and a phase-advance was also observed in rats challenged with ultradian 6-meal 690 schedules combined with caloric restriction (Mendoza et al., 2008). In the current study the acrophase of the body temperature rhythm was shifted toward daytime during the 6-meals-a-day feeding schedule, with a larger phase-advance in the hypocaloric fed mice compared to the isocaloric group. The sensitivity of the SCN clock to temperature cues has been a subject of recent debate because some studies found that the SCN may be shifted or not by temperature cycles (Buhr et al., 2010; Herzog group may be due to the deeper hypothermia in the calorie-restricted mice, i.e. the SCN and/or its downstream structures (e.g. secondary brain clocks) would be sensitive to the shifting effects of this deeper hypothermia.

\section{Glucose metabolism}

In contrast to the daily profiles of plasma NEFA, the daily rhythm of plasma glucose was highly altered by the 6-meal feeding schedule, with differential effects depending on whether the mice belonged to the hypocaloric or isocaloric group. In mice with ad libitum access to food, plasma glucose levels rise during daytime, as previously observed in other studies (e.g. Ahren, 2000; Grosbellet et al., 2015). While rats fed with the 6-meal schedule maintain their daily rhythm in plasma glucose at the same phase as rats fed ad libitum (La Fleur et al., 1999), in mice fed with 6-meal schedule daily plasma glucose levels became arrhythmic. In the hypocaloric group, in addition a relative hypoglycaemia occurred, most likely due to the caloric restriction (Mahoney et al., 2006).

Liver glycogen is crucial for maintaining blood glucose homeostasis. However, contrary to plasma glucose levels, the daily profiles in hepatic glycogen content remained unaltered, whatever the feeding condition of the mice. These findings suggest that daily rhythmicity of glycogen synthesis in these animals is dependent on SCN outputs (other than AVP) and/or light signals, most likely conveyed by autonomic inputs (Cailotto et al., 2008). Daytime restricted feeding in rats, however, results not only in increased gluconeogenesis, but also in a 12-h shift in the daily variations of hepatic glycogen content (Perez-Mendoza et al., 2014), thus indicating that daily restricted feeding can impact timing of glycogen synthesis. In the present study, the unaltered daily rhythm of glycogen content in the liver as opposed to the altered rhythms of plasma glucose suggest that changes in glycemia during ultradian feeding are mainly due to an altered timing in glucose utilization (e.g. by the skeletal muscles and/or the brain).

\section{Plasma corticosterone}

Contrary to the restricted-feeding paradigm, the ultradian 6-meal feeding schedule does not induce any pre-feeding rise of corticosterone, but increases the 
amplitude of daily rhythm of plasma corticosterone in rats (La Fleur et al., 1999). In the present study performed in mice, the daily rhythm of plasma corticosterone also showed a profound increase in amplitude during ultradian feeding conditions, but no shift of its acrophase. As for liver glycogen content, these findings suggest that daily rhythmicity of corticosterone concentrations during 6-meal schedule is controlled by SCN outputs (that would be different in that situation from the classical involvement of SCN AVP; Kalsbeek et al., 2012) and/or light signals probably conveyed by autonomic inputs (Husse et al., 2014; Ishida et al., 2005). A disappearance of the circadian 760 trough of circulating glucocorticoids is a hallmark of chronic stress (Dallman et al., 2000). The low morning levels of plasma corticosterone during 6-meals schedule (both the iso- and hypo-caloric groups) indicate that the basal activity of the hypothalamic-

765 pituitary-adrenal (HPA) axis is unaltered. By contrast, mice challenged with work for food display a large increase of corticosterone levels throughout daytime (van der Vinne et al., 2014), suggesting hyperactivity of the HPA axis. Thus, 6-meals schedule and work for 770 food paradigms differentially affect the HPA axis. The body mass loss may explain the increased evening peak of corticosterone during the ultradian feeding schedule, as mildly food-restricted rats fed at dusk also show an increased amplitude of the plasma corticos-

775 terone rhythm that seems to result from an increased sensitivity of ACTH to CRH (Garcia-Belenguer et al., 1993).

\section{Clock and metabolic gene expression in the liver}

In food-restricted animals fed during the resting peripheral clocks, especially those in the liver (Damiola et al., 2000; Stokkan et al., 2001). By contrast, in response to ultradian feeding, the liver clock is not affected as a whole (Kuroda 785 et al., 2012; Su et al., 2016a). Instead, as confirmed in the present study, distinct transcriptional changes are detected according to the clock gene considered (i.e. Clock, Rev-erbo, and Per2).

First, the phase of oscillations of the circadian 790 gene Clock was only slightly phase-advanced $(+1-3$ h) by the 6-meal feeding schedule. As CLOCK controls rhythmic synthesis of hepatic glycogen via transcriptional activation of Glycogen synthase 2 (Doi et al., 2010), it is worth noting that hepatic variations in glycogen content and Clock expression do not keep exactly the same phase-relationship according to feeding conditions, suggesting that rhythmic expression of Glycogen synthase 2 is also controlled by transcriptional factors other than CLOCK.

Second, diurnal expression of Rev-erb $\alpha$ in the liver was more phase-advanced $(+3-5 \mathrm{~h})$ by the $6-$ meals schedule, independent of the metabolic (isoor hypocaloric) status of the mice. Rhythmic transcription of Clock being controlled by REV-ERB $\alpha$ (Crumbley \& Burris, 2011), the smaller phaseadvance of liver Clock oscillations than those of Rev-erb $\alpha$ raise the possibility of post-translational modifications delaying transcriptional activity of REV-ERB $\alpha$. A daily hypocaloric meal also induces a phase-advanced hepatic expression of Rev-erb $\alpha$ (Feillet et al., 2006), suggesting that this common effect with ultradian feeding is unrelated to daily feeding signals, but may result from other cues (e.g. shifted metabolic or thermic cues; see below). Furthermore, an apparent $\sim 4$-h phaseadvance of this gene has also been reported in voles fed according to an ultradian rhythm (one meal every 2.5 h; van der Veen et al., 2006). Previous reports showed that liver expression of Rev-erb $\alpha$ is downregulated by refeeding after overnight fasting (Oike et al., 2011; Tahara et al., 2011). This modulatory effect does not readily explain the observed pattern of Rev-erb $\alpha$ expression under 6meal schedule, probably due to the short period of fasting ( $\sim 4 \mathrm{~h})$ between each food access). Together, these results indicate daily and ultradian feeding cues modulate the diurnal expression of Rev-erb $\alpha$ in the liver.

Third, the 6-meals schedule (isocaloric group) lead to prominent phase-advances $(+4 \mathrm{~h})$ of Per 2 expression in the liver, thus confirming previous data in PER2::LUC mice challenged with ultradian 6-meal feeding (Kuroda et al., 2012). An earlier rise of liver Per2 mRNA levels has also been reported in rats under 6-meal schedule (Cailotto et al., 2005) as well as in mice challenged with work for food (van der Vinne et al., 2014). Oxyntomodulin released by the gut after food intake up-regulates Per2 expression in the liver (Landgraf et al., 2015). This modulatory effect could partly explain the dampened amplitude of hepatic expression of Per2 during 6-meal schedule, 
though it did not abolish the daily rhythmicity (as would be expected if oxyntomodulin was the sole factor involved because food intake would trigger Per2 transcription every $4 \mathrm{~h}$, leading to constitutive levels throughout $24 \mathrm{~h}$ ). The larger shift in the hypocaloric group $(+7 \mathrm{~h})$ is also in accordance with previous findings in PER2::LUC mice chal850 lenged with ultradian 6-meal feeding combined to caloric restriction (Kuroda et al., 2012). These results show that hepatic oscillations of Per 2 are regulated not only by meal-timing cues, but also by metabolic cues associated with a reduction in the total energy intake. Among these cues, thermic signals due to phase-advanced body temperature (and deeper hypothermia in the case of ultradian hypocaloric feeding) may directly modulate liver expression of Per2 (Kornmann et al., 2007) which may, in turn, phase-advance the whole liver clock.

Several metabolic genes in the liver are regulated by the molecular clock, such as Sirt1, Ppar $\alpha$, $P g c-1 \alpha$ and $F g f 21$. In turn, SIRT1 causes deacetylation and degradation of PER2 and modulates 865 transcription of clock genes (such as Bmal1, Per2 and Cry1) due to $\mathrm{NAD}^{+}$dependent protein deacetylase activity (Asher et al., 2008). SIRT1 also regulates Ppar $\alpha$ expression (Purushotham et al., 2009) and interacts with $P g c-1 \alpha$ in the liver 870 (Rodgers et al., 2005). The hepatic expression of these metabolic genes was affected by ultradian feeding. However, the precise changes (mean, phase and/or amplitude) markedly differ according to the genes, suggesting a combination of 875 direct effects of 6-meal schedule conditions and modulation of phase-control by the liver clock (that was phase-advanced by ultradian feeding). Regarding $P g c-1 \alpha$ transcription, it was increased during 6-meals schedule in the isocaloric group, 880 and even more in the hypocaloric group, confirming previous data in mice challenged with another hypocaloric condition without daily feeding cues (i.e. alternate days of fasting for 3 months; Ranhotra, 2010). Levels of Sirt1 mRNA 885 levels tended to be increased in the hypocaloric group during ultradian feeding, an effect possibly linked to negative energy balance as up-regulated expression of Sirt1 is clearly observed in 24-h fasted mice (Hayashida et al., 2010). In addition, 890 the phase of diurnal expression of Sirt1 and Pgc$1 \alpha$ in the mouse liver was not affected by ultradian feeding, suggesting some uncoupling with the liver clockwork. Hepatic expression of Ppard was globally down-regulated by the isocaloric 6-meals schedule in contrast to the fastinginduced up-regulation of this gene (Hayashida et al., 2010), indicating that the duration of fasting is a critical parameter for transactivation of this gene.

Fgf21 expression is highly induced in the liver of mice fasted over $24 \mathrm{~h}$ (Lundasen et al., 2007). Here, Fgf21 expression was also increased during the 6-meals schedule, without a positive correlation with Ppara, one of its transcriptional regulators (Lundasen et al., 2007; Oishi et al., 2008). Because FGF21 can be released in the bloodstream and act on the central clock (Bookout et al., 2013), we assayed plasma FGF21 in mice challenged with the ultradian 6-meal schedule. In spite of higher hepatic expression, plasma levels of FGF21 were not increased during ultradian feeding (data not shown). This suggests that the $\sim 4$-h duration of fasting between 2 meals during ultradian feeding was too short to allow FGF21 synthesis and/or release. In any case, these findings seem to rule out a critical role of FGF21 as a hepatokine that would convey temporal cues associated with ultradian feeding to the brain.

\section{Clock and clock-controlled proteins in the SCN}

In contrast to the high sensitivity of peripheral clocks to the synchronizing effects of meal time, the SCN clock remains synchronized to the lightdark cycle in food-restricted rodents fed during daytime (Damiola et al., 2000; Stokkan et al., 2001), leading to the current view that the SCN is insensitive to feeding cues. The present study challenges this concept by highlighting molecular changes in the SCN of mice fed with an ultradian feeding schedule. These changes, including upregulated daily expression of the clock-controlled protein AVP and dampened oscillations of the two clock proteins PER1 and PER2, reveal that the daily alternation of feeding and fasting also participates in the normal functioning of the SCN. For AVP and PER2, the reducing effects of ultradian feeding on the amplitude of their oscillations were 
comparable between the isocaloric and hypocaloric

groups, while the magnitude of the downregulation of PER1 was more pronounced in the hypocaloric group. Of note, ultradian feeding combined with hypocaloric conditions does not produce the same temporal alterations in the SCN as those observed after daily caloric restriction (i.e. phaseadvances in daily oscillations of PER1 and AVP, Mendoza et al., 2007; or non-significant increased oscillations of PER2, van der Vinne et al., 2014), suggesting that caloric restriction is able to shift the SCN clock only when it is combined with a timed daily feeding cue. The effects of ultradian feeding under hypocaloric conditions, however, led to phase-advances of rest/activity rhythm comparable to those induced by daily caloric restriction (Mendoza et al., 2005) or by work for food (van der Vinne et al., 2014). This finding confirms that the behavioral phase-advances do not rely on the diurnal timing of a daily feeding cue (absent under ultradian feeding; Mendoza et al., 2008) and suggests that the neural changes leading to a more diurnal temporal niche of activity under food shortage occur in SCN pathways downstream to the clockwork (e.g. transforming growth factor $\alpha$ or prokineticin 2 signaling) and/or its downstream structures (i.e. secondary brain clocks).

Common voles often display ultradian rhythms of rest-activity and feeding-fasting. Furthermore, the number of SCN cells containing AVP has been negatively correlated with robustness of circadian rhythmicity in this species (Gerkema et al., 1994). Our data actually suggest that in mice, ultradian feeding may trigger up-regulated levels of AVP in the SCN.

Previous studies have already shown that daytime restricted feeding in rats modifies the daily pattern of AVP release from the SCN (i.e. delayed onset and earlier offset; Kalsbeek et al., 1998). Furthermore, daily caloric restriction also resulted in a phase-advance of the AVP rhythm in the SCN of mice fed at midday (Mendoza et al., 2007). When vasopressin signalling is altered, interneuronal coupling and the daily amplitude of transcriptional activity in the SCN is compromised (e.g. Li et al., 2009; Yamaguchi et al., 2013). The weaker oscillations of AVP during ultradian feeding may thus feedback within the SCN to the molecular clockwork and participate in dampened
SCN oscillations, as observed here for a reduced amplitude of PER1 and PER2 expression.

AVP released from the SCN terminals modulates the daily timing of glucocorticoid secretion by the adrenal glands, via inhibitory effects in the dorsomedial hypothalamic nuclei and the subparaventricular hypothalamic region (Kalsbeek et al., 1996). In mice fed according to the ultradian feeding schedule, the daily rhythm of plasma corticosterone is increased in amplitude and not shifted, while AVP protein expression is markedly increased. This apparent discrepancy raises the intriguing possibility that AVP in the SCN is actually synthesized, but not released as usual, in response to the 6-meal feeding schedule. In fact, a similar conclusion was drawn by the group of Gerkema because they showed that the increased levels of AVP in the SCN of arrhythmic voles are due to a decreased synaptic release of AVP (Jansen et al., 2000).

To sum up, this study highlights that when the daily feeding rhythm is abolished by introducing an ultradian periodicity of food intake, SCN function and daily rhythmicity of clock and metabolic genes in the liver are modified, glucose arrhythmicity occurs and amplitude of corticosterone rhythm increases. The additional impact of hypocaloric conditions under ultradian feeding highlights specific changes (not dependent on daily feeding cues or overnight fasting), including phase-advances of rest/activity and body temperature rhythms, more marked reduction of PER1 in the SCN and modified gene expression in the liver (e.g. larger shift of Per2 and up-regulated levels of $P g c-1 \alpha$ ). Thus, not only the timing of feeding and fasting, but also metabolic cues associated with hypocaloric conditions may affect the central and peripheral clocks.

\section{Acknowledgements}

We thank Sylviane Gourmelen and Dr. Dominique SageCiocca for their expert assistance with animal care and actimetry, respectively. We are also indebted to Pr. Paul Pévet for continuous support.

\section{Declaration of interest}

The authors report no conflict of interest. This work was supported by a doctoral fellowship from "Neurotime" Erasmus Mundus program (S.S.), and grants from Centre National de 
1035

la Recherche Scientifique and University of Strasbourg (P.V. and E.C.) and University of Amsterdam (A.K.).

\section{References}

Ahren B. (2000). Diurnal variation in circulating leptin is dependent on gender, food intake and circulating insulin in mice. Acta Physiol Scand. 169:325-331.

1040 Asher G, Gatfield D, Stratmann M, et al. (2008). SIRT1 regulates circadian clock gene expression through PER2 deacetylation. Cell. 134:317-328.

Bookout AL, de Groot MH, Owen BM, et al. (2013). FGF21 regulates metabolism and circadian behavior by acting on the nervous system. Nat Med. 19:1147-1152.

Bray MS, Young ME. (2009). The role of cell-specific circadian clocks in metabolism and disease. Obes Rev. 10(Suppl 2):6-13.

Buhr ED, Yoo SH, Takahashi JS. (2010). Temperature as a universal resetting cue for mammalian circadian oscillators. Science. 330:379-385.

Cailotto C, La Fleur SE, Van Heijningen C, et al. (2005). The suprachiasmatic nucleus controls the daily variation of plasma glucose via the autonomic output to the liver: are the clock genes involved? Eur J Neurosci. 22:2531-2540.

1055 Cailotto C, van Heijningen C, van der Vliet J, et al. (2008). Daily rhythms in metabolic liver enzymes and plasma glucose require a balance in the autonomic output to the liver. Endocrinology. 149:1914-1925.

Challet E. (2010). Interactions between light, mealtime and calorie restriction to control daily timing in mammals. J Comp Physiol B. 180:631-644.

Challet E, Pevet P, Vivien-Roels B, Malan A. (1997). Phaseadvanced daily rhythms of melatonin, body temperature, and locomotor activity in food-restricted rats fed during

1065 daytime. J Biol Rhythms. 12:65-79.

Challet E, Solberg LC, Turek FW. (1998). Entrainment in calorie-restricted mice: Conflicting zeitgebers and freerunning conditions. Am J Physiol Regul Integr Comp Physiol. 274:R1751-1761.

1070 Cho H, Zhao X, Hatori M, et al. (2012). Regulation of circadian behaviour and metabolism by REV-ERB-alpha and REV-ERB-beta. Nature. 485:123-127.

Crumbley C, Burris TP. (2011). Direct regulation of CLOCK expression by REV-ERB. PloS one. 6:e17290.

1075 Dallman MF, Akana SF, Bhatnagar S, et al. (2000). Bottomed out: metabolic significance of the circadian trough in glucocorticoid concentrations. Int J Obes Relat Metab Disord. 24(Suppl 2):S40-46.

Damiola F, Le Minh N, Preitner N, et al. (2000). Restricted 1080 feeding uncouples circadian oscillators in peripheral tissues from the central pacemaker in the suprachiasmatic nucleus. Genes Dev. 14:2950-2961.

Doi R, Oishi K, Ishida N. (2010). CLOCK regulates circadian rhythms of hepatic glycogen synthesis through transcrip-
Feillet CA, Mendoza J, Albrecht U, et al. (2008). Forebrain oscillators ticking with different clock hands. Mol Cell Neurosci. 37:209-221.

Feillet CA, Ripperger JA, Magnone MC, et al. (2006). Lack of food anticipation in Per2 mutant mice. Curr Biol. 16:2016-2022.

Froy O. (2011). Circadian rhythms, aging, and life span in mammals. Physiology. 26:225-235.

Garcia-Belenguer S, Oliver C, Mormede P. (1993). Facilitation and feedback in the hypothalamo-pituitaryadrenal axis during food restriction in rats. J Neuroendocrinol. 5:663-668.

Gerkema MP, Van der Zee EA, Feitsma LE. (1994). Expression of circadian rhythmicity correlates with the number of arginine-vasopressin-immunoreactive cells in the suprachiasmatic nucleus of common voles, Microtus arvalis. Brain Res. 639:93-101.

Grosbellet E, Dumont S, Schuster-Klein C, et al. (2015). Leptin modulates the daily rhythmicity of blood glucose. Chronobiol Int. 32:637-649.

Hayashida S, Arimoto A, Kuramoto Y, et al. (2010). Fasting promotes the expression of SIRT1, an NAD+-dependent protein deacetylase, via activation of PPARalpha in mice. Mol Cell Biochem. 339:285-292.

Herzog ED, Huckfeldt RM. (2003). Circadian entrainment to temperature, but not light, in the isolated suprachiasmatic nucleus. J Neurophysiol. 90:763-770.

Husse J, Leliavski A, Tsang AH, et al. (2014). The light-dark cycle controls peripheral rhythmicity in mice with a genetically ablated suprachiasmatic nucleus clock. FASEB J. 28:4950-4960.

Hut RA, Pilorz V, Boerema AS, et al. (2011). Working for food shifts nocturnal mouse activity into the day. PLoS One. 6:e17527.

Ishida A, Mutoh T, Ueyama T, et al. (2005). Light activates the adrenal gland: timing of gene expression and glucocorticoid release. Cell Metab. 2:297-307.

Jansen K, Van der Zee EA, Gerkema MP. (2000). Being circadian or not: vasopressin release in cultured SCN mirrors behavior in adult voles. Neuroreport. 11:3555-3558.

Jin X, Shearman LP, Weaver DR, et al. (1999). A molecular mechanism regulating rhythmic output from the suprachiasmatic circadian clock. Cell. 96:57-68.

Kalsbeek A, Strubbe JH. (1998). Circadian control of insulin secretion is independent of the temporal distribution of feeding. Physiol Behav. 63:553-558.

Kalsbeek A, van der Spek R, Lei J, et al. (2012). Circadian rhythms in the hypothalamo-pituitary-adrenal (HPA) axis. Mol Cell Endocrinol. 349:20-29.

Kalsbeek A, van Heerikhuize JJ, Wortel J, Buijs RM. (1996). A diurnal rhythm of stimulatory input to the hypothalamopituitary-adrenal system as revealed by timed intrahypothalamic administration of the vasopressin V1 antagonist. J Neurosci. 16:5555-5565.

Kalsbeek A, van Heerikhuize JJ, Wortel J, Buijs RM. (1998). Restricted daytime feeding modifies suprachiasmatic nucleus vasopressin release in rats. J Biol Rhythms. 13:18-29.
1090 
Kornmann B, Schaad O, Bujard H, et al. (2007). System-driven and oscillator-dependent circadian transcription in mice with a conditionally active liver clock. PLoS Biol. 5:e34.

1145 Kuroda H, Tahara Y, Saito K, et al. (2012). Meal frequency patterns determine the phase of mouse peripheral circadian clocks. Sci Rep. 2:711.

La Fleur SE, Kalsbeek A, Wortel J, Buijs RM. (1999). A suprachiasmatic nucleus generated rhythm in basal glucose concentrations. J Neuroendocrinol. 11:643-652.

Landgraf D, Tsang AH, Leliavski A, et al. (2015). Oxyntomodulin regulates resetting of the liver circadian clock by food. Elife. 4:e06253.

Li JD, Burton KJ, Zhang C, et al. (2009). Vasopressin receptor

1155 V1a regulates circadian rhythms of locomotor activity and expression of clock-controlled genes in the suprachiasmatic nuclei. Am J Physiol Regul Integr Comp Physiol. 296:R824-830.

Luby MD, Hsu CT, Shuster SA, et al. (2012). Food anticipa-

1160 tory activity behavior of mice across a wide range of circadian and non-circadian intervals. PLoS One. 7:e37992.

Lundasen T, Hunt MC, Nilsson LM, et al. (2007). PPARalpha is a key regulator of hepatic FGF21. Biochem Biophys Res Commun. 360:437-440.

1165 Mahoney LB, Denny CA, Seyfried TN. (2006). Caloric restriction in $\mathrm{C} 57 \mathrm{BL} / 6 \mathrm{~J}$ mice mimics therapeutic fasting in humans. Lipids Health Dis. 5:13.

Mendoza J, Drevet K, Pevet P, Challet E. (2008). Daily meal timing is not necessary for resetting the main circadian

1170 clock by calorie restriction. J. Neuroendocrinol. 20:251260.

Mendoza J, Gourmelen S, Dumont S, et al. (2012). Setting the main circadian clock of a diurnal mammal by hypocaloric feeding. J Physiol. 590:3155-3168.

1175 Mendoza J, Graff C, Dardente H, et al. (2005). Feeding cues alter clock gene oscillations and photic responses in the suprachiasmatic nuclei of mice exposed to a light/dark cycle. J Neurosci. 25:1514-1522.

Mendoza J, Pevet P, Challet E. (2007). Circadian and photic regulation of clock and clock-controlled proteins in the suprachiasmatic nuclei of calorie-restricted mice. Eur J Neurosci. 25:3691-3701.

Murat JC, Serfaty A. (1974). Simple enzymatic determination of polysaccharide (glycogen) content of animal tissues. Clin Chem. 20:1576-1577.

Nagashima K, Nakai S, Matsue K, et al. (2003). Effects of fasting on thermoregulatory processes and the daily oscillations in rats. Am J Physiol Regul Integr Comp Physiol. 284:R1486-1493.

1190 Oike H, Nagai K, Fukushima T, et al. (2011). Feeding cues and injected nutrients induce acute expression of multiple clock genes in the mouse liver. PLoS One. 6:e23709.

Oishi K, Uchida D, Ishida N. (2008). Circadian expression of FGF21 is induced by PPARalpha activation in the mouse liver. FEBS Lett. 582:3639-3642.

Perez-Mendoza M, Rivera-Zavala JB, Diaz-Munoz M. (2014). Daytime restricted feeding modifies the daily variations of liver gluconeogenesis: adaptations in biochemical and endocrine regulators. Chronobiol Int. 31:815-828.

Pfaffl MW. (2001). A new mathematical model for relative quantification in real-time RT-PCR. Nucleic Acids Res. 29: e45.

Portaluppi F, Smolensky MH, Touitou Y. (2010). Ethics and methods for biological rhythm research on animals and human beings. Chronobiol Int. 27:1911-1929.

Preitner N, Damiola F, Lopez-Molina L, et al. (2002). The orphan nuclear receptor REV-ERBalpha controls circadian transcription within the positive limb of the mammalian circadian oscillator. Cell. 110:251-260.

Purushotham A, Schug TT, Xu Q, et al. (2009). Hepatocytespecific deletion of SIRT1 alters fatty acid metabolism and results in hepatic steatosis and inflammation. Cell Metab. 9:327-338.

Ranhotra HS. (2010). Long-term caloric restriction up-regulates PPAR gamma co-activator 1 alpha (PGC-1alpha) expression in mice. Indian J Biochem Biophys. 47:272-277.

Reppert SM, Weaver DR. (2001). Molecular analysis of mammalian circadian rhythms. Annu Rev Physiol. 63:647-676.

Rodgers JT, Lerin C, Haas W, et al. (2005). Nutrient control of glucose homeostasis through a complex of PGC-1alpha and SIRT1. Nature. 434:113-118.

Stokkan KA, Yamazaki S, Tei H, et al. (2001). Entrainment of the circadian clock in the liver by feeding. Science. 291:490-493.

Su Y, Cailotto C, Foppen E, et al. (2016a). The role of feeding rhythm, adrenal hormones and neuronal inputs in synchronizing daily clock gene rhythms in the liver. Mol Cell Endocrinol. 422:125-131.

Su Y, Foppen E, Zhang Z, et al. (2016b). Effects of 6-meals-aday feeding and 6-meals-a-day feeding combined with adrenalectomy on daily gene expression rhythms in rat epididymal white adipose tissue. Genes Cells. 21:6-24.

Tahara Y, Otsuka M, Fuse Y, et al. (2011). Refeeding after fasting elicits insulin-dependent regulation of Per2 and Rev-erbalpha with shifts in the liver clock. J Biol Rhythms. 26:230-240.

Tokizawa K, Yoda T, Uchida Y, et al. (2015). Estimation of the core temperature control during ambient temperature changes and the influence of circadian rhythm and metabolic conditions in mice. J Therm Biol. 51:47-54.

Valle FP. (1981). Detrimental effects of irregular meals on rats' ability to adjust to meal feeding. Am J Psychol. 94:311.

van der Veen DR, Minh NL, Gos P, et al. (2006). Impact of behavior on central and peripheral circadian clocks in the common vole Microtus arvalis, a mammal with ultradian rhythms. Proc Natl Acad Sci USA. 103:3393-3398.

van der Vinne V, Riede SJ, Gorter JA, et al. (2014). Cold and hunger induce diurnality in a nocturnal mammal. Proc Natl Acad Sci USA. 111:15256-15260.

Yamaguchi Y, Suzuki T, Mizoro Y, et al. (2013). Mice genetically deficient in vasopressin $\mathrm{V} 1 \mathrm{a}$ and $\mathrm{V} 1 \mathrm{~b}$ receptors are resistant to jet lag. Science. 342:85-90.
1200

1205 